\title{
Sensitivity of modelled sulfate aerosol and its radiative effect on climate to ocean DMS concentration and air-sea flux
}

\author{
Jan-Erik Tesdal $^{1, a}$, James R. Christian ${ }^{2,3}$, Adam H. Monahan ${ }^{1}$, and Knut von Salzen ${ }^{3}$ \\ ${ }^{1}$ School of Earth and Ocean Sciences, University of Victoria, Victoria, British Columbia, Canada \\ ${ }^{2}$ Fisheries and Oceans Canada, Sidney, British Columbia, Canada \\ ${ }^{3}$ Canadian Centre for Climate Modelling and Analysis, Environment Canada, Victoria, British Columbia, Canada \\ anow at: Lamont-Doherty Earth Observatory, Columbia University, Palisades, New York, USA
}

Correspondence to: Jan-Erik Tesdal (tesdal@1deo.columbia.edu)

Received: 15 July 2015 - Published in Atmos. Chem. Phys. Discuss.: 4 September 2015

Revised: 10 June 2016 - Accepted: 29 July 2016 - Published: 1 September 2016

\begin{abstract}
Dimethylsulfide (DMS) is a well-known marine trace gas that is emitted from the ocean and subsequently oxidizes to sulfate in the atmosphere. Sulfate aerosols in the atmosphere have direct and indirect effects on the amount of solar radiation reaching the Earth's surface. Thus, as a potential source of sulfate, ocean efflux of DMS needs to be accounted for in climate studies. Seawater concentration of DMS is highly variable in space and time, which in turn leads to high spatial and temporal variability in ocean DMS emissions. Because of sparse sampling (in both space and time), large uncertainties remain regarding ocean DMS concentration. In this study, we use an atmospheric general circulation model with explicit aerosol chemistry (CanAM4.1) and several climatologies of surface ocean DMS concentration to assess uncertainties about the climate impact of ocean DMS efflux. Despite substantial variation in the spatial pattern and seasonal evolution of simulated DMS fluxes, the global-mean radiative effect of sulfate is approximately linearly proportional to the global-mean surface flux of DMS; the spatial and temporal distribution of ocean DMS efflux has only a minor effect on the global radiation budget. The effect of the spatial structure, however, generates statistically significant changes in the global-mean concentrations of some aerosol species. The effect of seasonality on the net radiative effect is larger than that of spatial distribution and is significant at global scale.
\end{abstract}

\section{Introduction}

The global shortwave radiation budget is influenced by sulfate aerosols in two ways: directly via scattering and indirectly through changes to the radiative properties of clouds (as sulfate droplets act as cloud condensation nuclei, CCN) (Charlson et al., 1987; Andreae and Crutzen, 1997). An important natural source of atmospheric sulfate is the oxidation of biogenic dimethylsulfide (DMS) which has outgassed from the ocean surface (Andreae and Raemdonck, 1983; Bates et al., 1992). Particular interest in the role of DMS in the atmospheric sulfur cycle arose following the hypothesis by Charlson et al. (1987) of a negative feedback on ocean surface temperature changes mediated by cloud albedo and phytoplankton productivity: the so-called "CLAW hypothesis". However, subsequent studies have suggested that the influence of DMS on CCN formation may be weak (Quinn and Bates, 2011; Woodhouse et al., 2010, 2013) and that the associated albedo changes are uncertain (Stevens and Feingold, 2009). Furthermore, a comprehensive understanding of the physical and biogeochemical processes that control the production of DMS and its removal from the ocean has not yet been established. The production and consumption of DMS in the water column involve a range of biotic and abiotic processes (Stefels et al., 2007). While outgassing of DMS from the ocean surface is of interest because of its climatic influence, it is a relatively minor term in the ocean DMS budget. Potentially as little as 1-10\% of ocean DMS production reaches the atmosphere (Malin et al., 1992; Bates et al., 1994). While some model experiments have found evidence of enhanced DMS fluxes under 
global warming (Cameron-Smith et al., 2011; Gabric et al., 2004, 2005), others have suggested that the changes are weak (Bopp et al., 2003; Vallina et al., 2007) or might actually be negative (Kloster et al., 2007; Six et al., 2013). While the strength and character of the influence of DMS on global climate are uncertain, little work has been done to quantify the contribution of individual components of this uncertainty. The present study uses a comprehensive global atmospheric circulation model to quantify the uncertainty associated with surface concentration fields of DMS and air-sea flux parameterizations.

Kettle et al. (1999) (K99) compiled a global DMS database for the development of DMS climatologies and of parameterizations for use in modelling studies (Halloran et al., 2010). However, spatial and temporal variations in DMS concentration are not well constrained by this database, because the number of available observations is still relatively small. There are large temporal and spatial variations in the sea surface concentration of DMS (Asher et al., 2011; Tortell, 2005; Tortell et al., 2011), and the current observational dataset provides only sparse information from wide expanses of the ocean. In the absence of measurements uniformly distributed in space and time to fully characterize the spatial and temporal variability of DMS, interpolation and extrapolation schemes are required to construct continuous, observationally based global fields of DMS concentration (Kettle et al., 1999; Lana et al., 2011). While the estimates generally indicate continuously elevated concentrations in tropical latitudes in contrast to low winter and high summer concentrations in middle and high latitudes, these fields remain highly uncertain due to inadequate sampling. For example, observationally based climatologies such as those of $\mathrm{K} 99$ and Lana et al. (2011) (L10, released in 2010) show "bulls-eye" maxima that likely do not reflect the real distribution of DMS. The range of possible surface DMS fields increases when climatologies based on diagnostic or prognostic models are considered (Tesdal et al., 2016).

The parameterization of air-sea fluxes is also uncertain. Several different parameterizations of the piston velocity in terms of wind speed have been used in modelling studies (e.g., Liss and Merlivat, 1986; Wanninkhof, 1992; Nightingale et al., 2000), leading to substantially different flux fields for a given concentration field (Tesdal et al., 2016). Furthermore, it has been found that neglect of air-side resistance in the flux formulation (as is often done) can change estimates of fluxes by about $10 \%$ (McGillis et al., 2000; Tesdal et al., 2016). The large differences in DMS sea surface concentration fields between different climatologies and in flux parameterizations can cause substantial variation in estimated fluxes (Tesdal et al., 2016).

An important question is how the uncertainty in fluxes translates into an uncertainty in the climate response. Although DMS fields show large differences in spatial pattern and seasonality, the differences in global- and annual-mean fluxes are considerably smaller. As well, the climatic sig- nificance of relatively small-scale concentration features remains uncertain, given the large-scale structure of the winds which drive the fluxes and the subsequent transport and oxidation to sulfate aerosol. Hereafter, net changes in the energy budget at the top of the atmosphere (TOA) due to changes in concentrations of DMS-derived sulfate will be referred to as the radiative effect, which is sometimes also referred to as radiative forcing.

Comprehensive atmospheric general circulation models (AGCMs) are the natural tool for assessing the uncertainty in the climatic influence of oceanic DMS fluxes. Using different DMS concentration fields as boundary conditions, the resulting changes in the atmospheric burden of sulfur species and radiative effect can be assessed. Previous modelling studies have focused on the effect of DMS on aerosol, CCN and TOA radiation budget by scaling a single DMS field (e.g., Gunson et al., 2006; Thomas et al., 2011). Using a coupled atmosphere-ocean model, Grandey and Wang (2015) estimated a radiative perturbation of -1.3 to $-1.5 \mathrm{~W} \mathrm{~m}^{-2}$ when increasing global total DMS flux from 18 to $46 \mathrm{TgS} \mathrm{yr}^{-1}$. There has not been much discussion of the climatic effect of differences in the spatial and temporal structure of DMS flux (Woodhouse et al., 2013).

A recent study demonstrated substantial impacts on cloud properties and the radiation budget by using the updated L10 climatology versus the previous K00 (Mahajan et al., 2015). Even though L10 represents a substantial extension of K00, the spatial and temporal patterns are still fairly similar compared to most other available DMS reconstructions (Tesdal et al., 2016). However, the substitution of L10 for K00 results in increases in the aerosol effect on net TOA radiation of about $20 \%$. The potentially large sensitivity of climate response to DMS climatology demonstrated by Mahajan et al. (2015) motivates the question of how important spatial and temporal variations are to atmospheric properties and radiative effects relative to changes in the global total DMS flux. This question is addressed in the present study using the fourth-generation Canadian Atmospheric Global Climate Model (CanAM4.1).

Previous simulations with the Canadian atmosphere model used ocean emissions of DMS calculated from one specific climatology (K99) and one gas flux parameterization, that of Liss and Merlivat (1986) (LM86). In this study, we assess the uncertainty in the climatic influence of DMS with simulations with CanAM4.1 using different surface concentration climatologies and flux parameterizations. As our baseline reference, we use the recently developed observationally based climatology of L10. These simulation results are compared to those obtained using three different climatologies: K99, an updated version of K99 from Kettle and Andreae (2000) (K00), and the empirical model of Anderson et al. (2001) (AN01). AN01 was shown by Tesdal et al. (2016) to produce global-mean DMS fluxes similar to those associated with the observationally based climatologies. To further assess the importance of spatial and temporal structure in the 


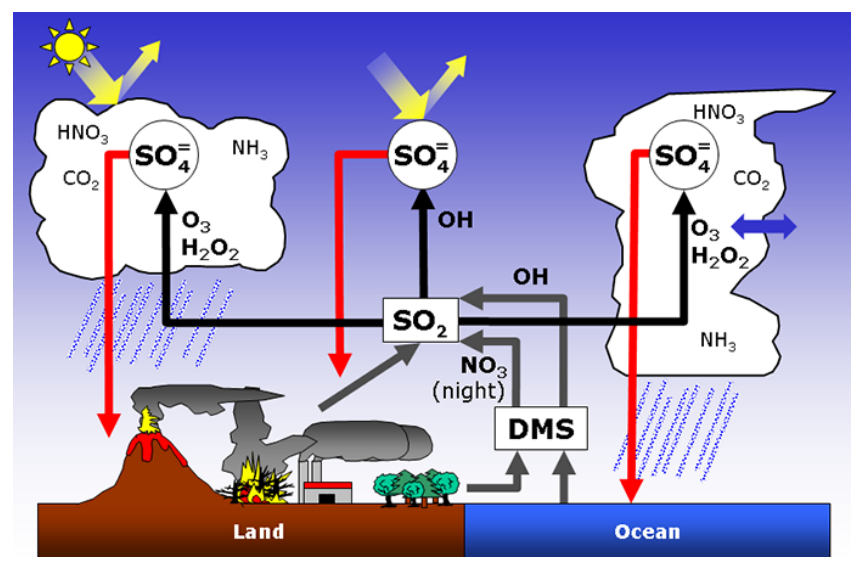

Figure 1. Schematic representation of the sulfur cycle and radiative effects of sulfate aerosols in CanAM4.1. In each grid cell, the model accounts for sources and sinks of sulfate aerosol $\left(\mathrm{SO}_{4}^{2-}\right)$, $\mathrm{SO}_{2}$, and DMS. $\mathrm{SO}_{2}$ is emitted from volcanos, fires, and anthropogenic sources. DMS is mainly emitted from the oceans, but there are also some terrestrial sources. DMS is oxidized to $\mathrm{SO}_{2}$ by $\mathrm{OH}$ during the day and by $\mathrm{NO}_{3}$ during the night. $\mathrm{SO}_{2}$ is oxidized to sulfate both within clouds and under clear-sky conditions. In-cloud oxidation of sulfur and wet deposition is treated separately for layer (stratiform) and convective clouds. For both types of clouds, oxidation occurs via ozone $\left(\mathrm{O}_{3}\right)$ and hydrogen peroxide $\left(\mathrm{H}_{2} \mathrm{O}_{2}\right)$. Oxidation rates depend on the $\mathrm{pH}$ of the cloud water, which depends on the concentrations of nitric acid $\left(\mathrm{HNO}_{3}\right)$, ammonia $\left(\mathrm{NH}_{3}\right)$, and carbon dioxide $\left(\mathrm{CO}_{2}\right)$.

DMS concentration fields, simulations were carried out with the L10 climatology replaced with its spatial mean (retaining month-to-month changes) and with its annual mean (retaining spatial variability). Two flux parameterizations are considered: LM86 and that of Nightingale et al. (2000) (N00). Section 2 describes the AGCM and the details of the numerical experiments. The results of the simulations are presented in Sect. 3, followed by a discussion of the results in Sect. 4 . Conclusions are presented in Sect. 5.

\section{Methods}

\subsection{Model description}

All model simulations presented in this study were made with CanAM4.1, the atmosphere component of the Canadian Earth System Model. CanAM4.1 is a slightly newer version of CanAM4 (von Salzen et al., 2013) with improved diagnostic capabilities. Model dynamics are computed spectrally with a horizontal resolution of T63, equivalent to a $128 \times 64$ linear grid. The model has 49 layers in the vertical extending from the surface to $1 \mathrm{hPa}$, with a spacing of about $100 \mathrm{~m}$ at the surface and increasing monotonically at higher altitudes.

Figure 1 presents a schematic of the sulfur cycle and the radiative effects of sulfate aerosols as represented in
CanAM4.1. The ocean efflux of DMS is a source of aerosols via oxidation to sulfur dioxide $\left(\mathrm{SO}_{2}\right)$, which in turn is oxidized to form sulfate $\left(\mathrm{SO}_{4}^{2-}\right)$. The air-sea gas transfer of DMS is calculated with wind speed from the model, while ice cover and sea surface temperature (SST) are specified using a climatological dataset from the Atmospheric Model Intercomparison Project (AMIP) (Hurrell et al., 2008). In addition to the ocean source, the model also accounts for DMS fluxes from the terrestrial biosphere using specified monthly mean fields (Spiro et al., 1992). Besides DMS, the model also includes additional terrestrial sources of sulfur to the atmosphere: monthly mean emissions of gas phase $\mathrm{SO}_{2}$ from fires (i.e., biomass burning) and anthropogenic sources, as well as volcanic emissions (Dentener et al., 2006). Anthropogenic aerosol and aerosol precursor emissions are used based on Representative Concentration Pathway (RCP) 4.5 from the fifth phase of the Coupled Model Intercomparison Project (CMIP5; Lamarque et al., 2010; Moss et al., 2010).

Transport, dry and wet deposition, and chemical transformations of sulfur species are all accounted for in CanAM4.1 (von Salzen et al., 2013). DMS is oxidized to $\mathrm{SO}_{2}$ by hydroxyl radicals $(\mathrm{OH})$ during daylight hours and by nitrate radicals $\left(\mathrm{NO}_{3}\right)$ at night. Sulfate aerosol $\left(\mathrm{SO}_{4}^{2-}\right)$ production is modelled by in-cloud and gas-phase (clear-sky) oxidation of $\mathrm{SO}_{2}$. In-cloud production is treated differently in layer and convective clouds. The presence of ozone $\left(\mathrm{O}_{3}\right)$ and hydrogen peroxide $\left(\mathrm{H}_{2} \mathrm{O}_{2}\right)$ as oxidants is a requirement for both types of clouds, and oxidation rates are modelled as $\mathrm{pH}$-dependent (von Salzen et al., 2000). The in-cloud oxidation rate in deep convective clouds is calculated in proportion to the cloud fraction, which is determined based on Slingo (1987). As CanAM4.1 does not have a fully interactive chemical transport module, it uses specified oxidant concentrations $(\mathrm{OH}$, $\mathrm{NO}_{3}, \mathrm{O}_{3}, \mathrm{H}_{2} \mathrm{O}_{2}$ ) from the Model for Ozone and Related Chemical Tracers (MOZART; Brasseur et al., 1998). Ammonia $\left(\mathrm{NH}_{3}\right)$ and ammonium $\left(\mathrm{NH}_{4}^{+}\right)$concentration fields are also specified (Dentener and Crutzen, 1994).

The removal of sulfate aerosol takes place through wet and dry deposition. The dry deposition flux of sulfate simply depends on the concentration within the model layer adjacent to the surface along with a defined dry deposition velocity (Lohmann et al., 1999). Wet deposition, as with the in-cloud oxidation outlined above, is treated separately for layer and convective clouds. Within convective clouds, scavenging is modelled as a function of precipitation (von Salzen et al., 2000). Wet deposition fluxes from in-cloud scavenging of aerosols in layer clouds depend on local rates of conversion of cloud water to rainwater (Croft et al., 2005). Scavenging by falling rain droplets beneath convective clouds is parameterized using a mean collection efficiency (Berge, 1993).

CanAM4.1 accounts for sulfate aerosol, organic carbon aerosol, black carbon, sea salt, and dust as separate species using a bulk aerosol scheme (Lohmann et al., 1999; Croft et al., 2005). In the CanAM4.1 version used in this study, the cloud droplet number concentration (CDNC) depends only 
on the local concentration of sulfate. The empirical parameterization of Dufresne et al. (2005) is used. This parameterization relates CDNC to the concentration of sulfate as

$\mathrm{CDNC}=60\left[\mathrm{SO}_{4}^{2-}\right]^{0.2}$,

where $\mathrm{CDNC}$ is in number $\mathrm{cm}^{-3}$ and $\left[\mathrm{SO}_{4}^{2-}\right]$ is the sulfate concentration in $\mu \mathrm{g} \mathrm{m}^{-3}$. For this relationship, a lower bound on CDNC of $1 \mathrm{~cm}^{-3}$ is used.

CanAM4.1 calculates the direct radiative effect of scattering by aerosols and the first indirect radiative effect in which cloud optical properties are influenced by aerosol concentrations. Effects of aerosols on the conversion of cloud water to precipitation (second indirect effect) are not considered in the current version of CanAM4.1. Direct effect calculations account for scattering and absorption using Mie theory. These processes depend on aerosol mass and relative humidity: sulfate aerosols scatter radiation more efficiently at higher relative humidity as they swell in size to establish thermodynamic equilibrium according to Raoult's law. The overall efficiency of the scattering effect also varies with wavelength and aerosol concentration. The first indirect effect is computed by determining the effective radius of cloud droplets based on the relationship between sulfate aerosol and CDNC described above. Smaller droplets are more efficient at scattering solar radiation than larger droplets. Given the much greater cloud fraction of layer (stratiform) clouds compared to convective clouds, the indirect effect is only applied in layer clouds. Within each model grid cell, the cloud forcing is determined as the difference between the net radiative fluxes for all-sky and clear-sky only.

The bulk scheme considered in this study is simpler than approaches that consider aerosol microphysics in detail (e.g., Bellouin et al., 2013). However, based on the few available studies comparing results from different models with bulk and microphysics schemes, we do not see evidence of considerable improvement in radiative forcing estimates based on simulations with microphysics schemes relative to bulk schemes (Schulz et al., 2006; Koch et al., 2009; Quaas et al., 2009).

\subsection{Description of the model experiments}

A series of model experiments was conducted to investigate the effects of different sea surface DMS climatologies and gas transfer formulations on net TOA radiation and the atmospheric burdens of DMS, $\mathrm{SO}_{2}$, and sulfate aerosol. These experiments are listed in Table 1 . The surface concentration fields considered are the observationally derived K99, K00, and L10 and the empirical algorithm AN01, which computes DMS concentration from chlorophyll, nutrient concentrations, and solar irradiance (Anderson et al., 2001). Of the various diagnostic and prognostic models of DMS used in global models, AN01 was found to produce global-mean DMS fluxes closest to L10 (although the spatial structures of the fluxes differ considerably; Tesdal et al., 2016). As well, we consider simulations with the L10 climatology replaced by its spatial mean (but retaining the seasonal cycle) and with L10 replaced by its annual mean (retaining the spatial structure).

The L10 climatology is an update to the K99 and K00 climatologies, incorporating a larger set of DMS observations. By comparing these three climatologies, we can assess the consequences of using an updated DMS concentration climatology for air-sea fluxes and climate response (Mahajan et al., 2015), helping quantify the importance of continued improvements to estimates of the seawater DMS field. Furthermore, K99 and K00 have been used in a number of previous studies (e.g., Thomas et al., 2010, 2011; Woodhouse et al., 2010, 2013). By including K99 and K00, we allow for the comparison of our results with those of previous studies.

Because the wind speed and DMS concentration are correlated, the fluxes associated with the temporally invariant or spatially uniform concentration fields do not equal the global-mean flux associated with the spatially and temporally varying concentration. Because we wish to distinguish the direct climatic influence of spatial and temporal structure in DMS fluxes from the global-mean flux, the temporally or spatially uniform DMS concentration fields were rescaled to produce the same total flux as the reference simulation. The scaling factors were determined with offline calculations using ERA-Interim reanalysis wind, sea ice, and SST (Dee et al., 2011). For the temporally invariant run, a single scaling factor was determined, while for the spatially uniform case scaling factors were determined for each monthly field. Two additional simulations were conducted with spatial and temporal patterns given by climatologies other than L10 (K99 and AN01) but scaled to have the same global-mean flux as L10 (Table 1).

The DMS flux formulations considered are L86 and N00 (Liss and Merlivat, 1986; Nightingale et al., 2000). For N00, we conducted simulations with and without air-side resistance $\left(\gamma_{\mathrm{a}}\right)$ accounted for in the flux formulation. A detailed discussion of different DMS concentration climatologies and flux formulations is presented in Tesdal et al. (2016).

The control simulation (L10 \& N00 \& $\gamma_{\mathrm{a}}$ ) was carried out using the L10 DMS concentration field with the N00 wind parameterization scheme and accounting for air resistance (Nightingale et al., 2000; Tesdal et al., 2016). The L10 climatology was used for the control simulation as it is in closest agreement with the observational database, including observations made since it was developed (Tesdal et al., 2016).

All DMS concentration fields were prepared offline before model simulations were carried out. The AN01 climatology was constructed using observed chlorophyll, light, and nutrient fields (as outlined in Tesdal et al., 2016). Differences between the model runs result from differences in DMS concentration fields, flux parameterizations, and internal variability in the model. Other aspects of the model, such as oxidation pathways and cloud microphysics, are the same for all model experiments. 
Table 1. List of model sensitivity experiments.

\begin{tabular}{|c|c|}
\hline Name & Description \\
\hline L10 \& N00 \& $\gamma_{\mathrm{a}}$ & Control experiment \\
\hline L10 \& N00 & No air resistance \\
\hline L10 \& LM86 & LM86 flux scheme, no air resistance \\
\hline K99 \& LM86 & $\begin{array}{l}\text { Older K99 climatology instead of L10 climatology, LM86 flux scheme, } \\
\text { no air resistance }\end{array}$ \\
\hline K99 \& N00 \& $\gamma_{\mathrm{a}}$ & As control, but with K99 climatology \\
\hline K00 \& N00 \& $\gamma_{\mathrm{a}}$ & As control, but with K00 climatology \\
\hline K99* \& N00 \& $\gamma_{\mathrm{a}}$ & As control, but with K99 scaled to L10 global flux \\
\hline AN01* \& N00 \& $\gamma_{\mathrm{a}}$ & As control, but with AN01 scaled to L10 global flux \\
\hline Temporally invariant & $\begin{array}{l}\text { L10 annual-mean field for all months scaled to the original L10 } \\
\text { global flux }\end{array}$ \\
\hline Spatially uniform & $\begin{array}{l}\text { Spatially uniform fields with monthly global-mean L10 concentration } \\
\text { scaled to the original L10 global flux }\end{array}$ \\
\hline
\end{tabular}

In order to assess internal variability, an ensemble of three 5-year-long runs were produced for each model configuration. Each ensemble member uses the exact same model configuration, but in each a different seed was used in the random number generator used in the radiation code. Ensemble averages are statistically more robust estimates of the climate influence of DMS than any individual member of the ensemble. The spread among ensemble members indicates the magnitude of the response to changes in DMS fluxes relative to internal variability. All simulations are carried out for the period from January 2003 to December 2008, with the first year discarded as a spin-up period.

\section{Results}

\subsection{Assessment of simulated sulfate aerosol}

The assessment of simulations of natural sulfate aerosol in the marine troposphere is challenging given a lack of chemical observations in remote regions of the ocean where the contribution of DMS oxidation to sulfate aerosol concentration is most significant. Even where chemical measurements exist, the relative contribution of ocean DMS emissions to net sulfate production cannot be directly observed. In an attempt to assess model results for sulfate, observed sulfate concentrations from ship-based measurements were compiled from available datasets obtained from the NOAA PMEL Atmospheric Chemistry Data Server (http://saga.pmel.noaa.gov/ data). Figure 2 shows a map of the cruise transects from which observational datasets were drawn. The datasets contain multiple types of sulfate, but only total non-sea-salt sulfate (nss- $\mathrm{SO}_{4}^{2-}$ ) was considered (sum of all size fractions present).

For comparisons with these datasets, simulated sulfate concentrations from the control run were compared to the measurements, matching simulated and observed nearsurface concentrations according to nearest location and month of the year. This yields a correlation of 0.57 between simulated and observed concentrations (Fig. 3). The mean simulated concentration in Fig. 3 of $0.96 \pm 0.86 \mu \mathrm{g} \mathrm{m}^{-3}$ for all available data is lower than the corresponding observed value of $1.84 \pm 2.31 \mathrm{\mu g} \mathrm{m}^{-3}$ (i.e., model underestimate of $48 \%)$.

In an attempt to characterize the impact of anthropogenic pollution on the results, the data were grouped by latitude (Fig. 3a). Simulated and observed concentrations between the Equator and $50^{\circ} \mathrm{N}$ are relatively high, which can be partly explained by contributions of anthropogenic emissions to sulfate concentrations. Without these data, the agreement between mean simulated and measured concentrations improves noticeably $\left(0.49 \pm 0.13 \mu \mathrm{g} \mathrm{m}^{-3}\right.$ in the model vs. $0.72 \pm 0.58 \mu \mathrm{g} \mathrm{m}^{-3}$ in observations, an underestimate of $32 \%$, Fig. 3a).

To further characterize the impact of DMS emissions on atmospheric sulfate concentration, the fraction of sulfate from ocean DMS emissions was diagnosed based on model simulations with and without ocean DMS emissions. The diagnosed fraction from these simulations is in good overall agreement with results from Gondwe et al. (2003), which show a large influence of DMS emissions on near-surface sulfate concentration in the Southern Hemisphere and at high latitudes in the Northern Hemisphere. As shown in Fig. 3b, low sulfate concentrations tend to be associated with a high fraction of sulfur originating from DMS emissions. There is good agreement between mean simulated and observed concentrations where this fraction exceeds $40 \%(0.48 \pm 0.26$ $\mu \mathrm{g} \mathrm{m}^{-3}$ in the model versus $0.72 \pm 0.55 \mu \mathrm{g} \mathrm{m}^{-3}$ in observations, Fig. 3a), with a Pearson correlation coefficient of 0.62 .

Comparisons in Fig. 3 are influenced by the use of climatological instead of actual emissions in the model. In addition, differences between climatological and actual meteorological situations and the relatively low spatial resolution of the model need to be considered when interpreting simulated sulfate concentrations. These factors may largely ex- 


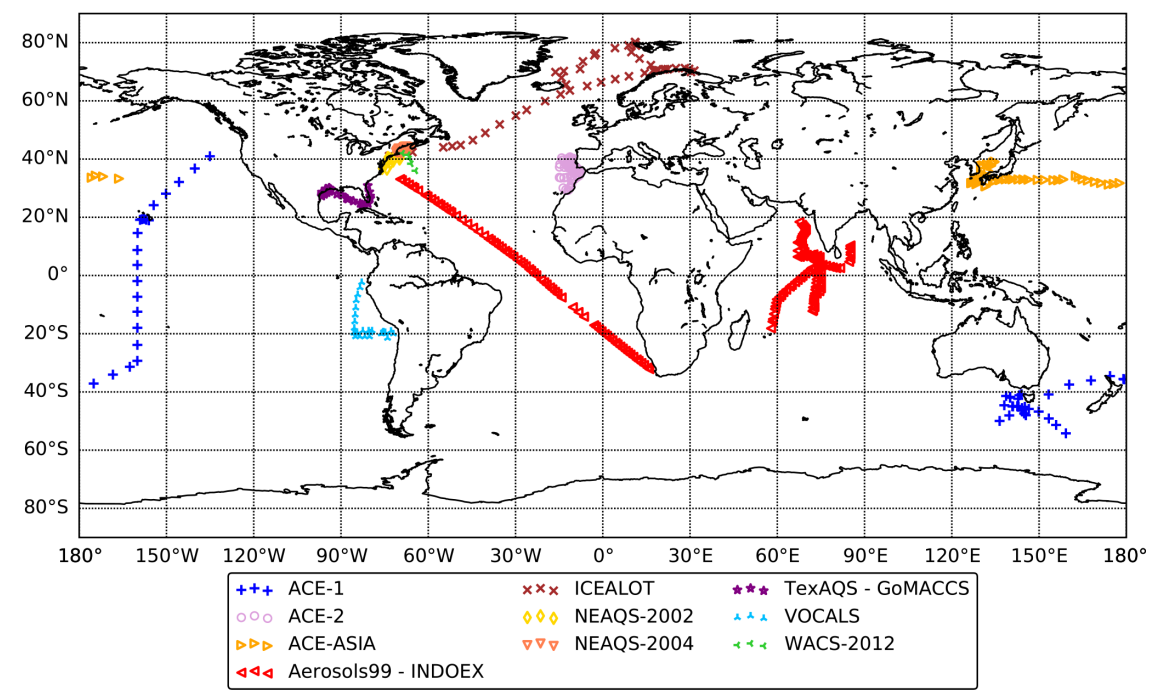

Figure 2. Map showing the locations of the nss- $\mathrm{SO}_{4}^{2-}$ measurements used in the model assessment. All cruise data were obtained from the NOAA PMEL Atmospheric Chemistry Data Server (http://saga.pmel.noaa.gov/data) collected by ACE-1 (October-December 1995), ACE-2 (June-July 1997), ACE-ASIA (March-April 2001), Aerosols99-INDOEX (January-March 1999), ICEALOT (March-April 2008), NEAQS (July-August 2002), NEAQS (July-August 2004), TexAQS-GoMACCS (July-September 2006), VOCALS (October-December 2008), and WACS (August 2012).

plain the lower variability in simulated concentrations compared to observations. However, even if local differences in spatial or temporal variability in sulfate concentrations exist they are unlikely to greatly influence the global climate, based on an analysis of results with variable DMS emissions in Sect. 3.4.

In summary, the analysis of sulfate concentrations over the ocean confirms that a substantial fraction of the sulfate concentrations in observations and the model are related to emissions of sulfur from the ocean, with good overall agreement in regions that are most strongly affected by DMS emissions. This provides evidence of realistic simulations of atmospheric DMS sources and aerosol removal processes in the marine atmosphere. In addition, simulated relationships between sulfate aerosol concentrations and simulated cloud microphysical properties in the model agree well with relationships that are based on observed cloud properties over the ocean (Ma et al., 2010; von Salzen et al., 2013), which provides evidence for realistic responses of simulated radiative effects of sulfate aerosol to DMS emissions in the model.

\subsection{Comparison between model and reanalysis flux estimates}

Before analyzing the climatic influence of differences in DMS fluxes, we will compare the global- and annual-mean DMS fluxes in the different simulations to the fluxes calculated with the ERA-Interim reanalysis SST, sea ice, and wind speed fields over the same time period as the model simulations (Table 2). The global- and annual-mean flux is generally higher in the CanAM4.1 simulation than when reanalysis fields are used: it is $22-24 \%$ larger with N00 (with or without air resistance) and $14 \%$ larger with LM86. These differences must result primarily from differences in the wind fields, because SST and sea ice cover are specified in all simulations with AMIP boundary conditions and are very similar to the ERA-Interim fields. The winds are overall somewhat stronger in the model than in the reanalysis product: the annual-mean surface wind speed is $17 \%$ higher on average in CanAM4.1. The frequency distribution and seasonality of the winds also differ slightly between the model and observations (not shown). Fluxes are particularly sensitive to high wind speeds, and slight changes in the wind distribution can be magnified in the DMS flux. Consistent with the results of Tesdal et al. (2016), the DMS flux calculated with the L10 DMS concentration field is higher than that calculated with K99 or K00, independent of which gas transfer formulation is used.

Because the DMS fluxes computed with the model wind fields differ substantially from those computed by reanalysis winds, we expect the simulated climatic influence of DMS to be biased. However, as our focus is on the sensitivity of the climatic influence of DMS to changes in DMS fluxes rather than the absolute strength of the effect, this model bias is not expected to affect our results.

\subsection{Fluxes and atmospheric sulfur burdens}

Changes in the DMS concentration climatology and the flux formulation result in substantial changes in the global-mean flux (including both ocean and terrestrial sources; Table 3). The change relative to the control simulation ranges from 
Table 2. Ocean emissions of DMS from CanAM4.1 and offline calculations with reanalysis fields. DMS flux is derived for the time period of the model simulations (January 2004 to December 2008). Quantities in parentheses are percentage changes relative to the reference run $\left(\mathrm{L} 10 \& \mathrm{~N} 00 \& \gamma_{\mathrm{a}}\right)$.

\begin{tabular}{|c|c|c|c|c|}
\hline \multirow[t]{2}{*}{ Model runs } & \multicolumn{2}{|c|}{ CanAM4.1 } & \multicolumn{2}{|c|}{ ERA-Interim } \\
\hline & $\begin{array}{r}\text { Mean flux } \\
\mu \operatorname{mol~m}{ }^{-2} d^{-1}\end{array}$ & $\begin{array}{l}\text { Total flux } \\
\operatorname{TgS~yr}^{-1}\end{array}$ & $\begin{array}{r}\text { Mean flux } \\
\mu \text { mol m} \mathrm{m}^{-2} \mathrm{~d}^{-1}\end{array}$ & $\begin{array}{l}\text { Total flux } \\
\operatorname{TgS}_{y r}{ }^{-1}\end{array}$ \\
\hline L10 \& N00 \& $\gamma_{\mathrm{a}}$ & 7.02 & 28.9 & 5.72 & 23.6 \\
\hline L10 \& N00 & 7.60 & $31.3(+8 \%)$ & 6.13 & $25.3(+7 \%)$ \\
\hline L10 \& LM86 & 4.94 & $20.4(-29 \%)$ & 4.34 & $17.9(-24 \%)$ \\
\hline K99 \& LM86 & 4.44 & $18.3(-37 \%)$ & 3.89 & $16.0(-32 \%)$ \\
\hline K99 \& N00 \& $\gamma_{a}$ & 6.31 & $25.9(-10 \%)$ & 5.11 & $21.0(-11 \%)$ \\
\hline $\mathrm{K} 00 \& \mathrm{~N} 00 \& \gamma_{\mathrm{a}}$ & 6.02 & $24.7(-14 \%)$ & 4.90 & $20.3(-15 \%)$ \\
\hline
\end{tabular}

Table 3. Annual DMS emissions, oxidation rates, and atmospheric burdens of $\mathrm{DMS}, \mathrm{SO}_{2}$, and $\mathrm{SO}_{4}^{2-}$.

\begin{tabular}{|c|c|c|c|c|c|c|}
\hline \multirow[t]{2}{*}{ Model runs } & \multicolumn{3}{|c|}{ Fluxes and oxidation rates $\left(\mathrm{TgS} \mathrm{yr}^{-1}\right)$} & \multicolumn{3}{|c|}{ Atmospheric burdens ( $\mathrm{TgS}$ ) } \\
\hline & Emissions $^{1}$ & $\begin{array}{r}\text { Oxidation } \\
\text { by } \mathrm{OH}\end{array}$ & $\begin{array}{r}\text { Oxidation } \\
\text { by } \mathrm{NO}_{3}\end{array}$ & DMS & $\mathrm{SO}_{2}$ & $\mathrm{SO}_{4}^{2-}$ \\
\hline L10 \& N00 \& $\gamma_{\mathrm{a}}$ & 29.8 & 18.1 & 11.7 & 0.24 & 0.40 & 0.67 \\
\hline L10 \& N00 & 32.2 & 19.6 & 12.6 & 0.26 & 0.42 & 0.69 \\
\hline L10 \& LM86 & 21.2 & 12.9 & 8.31 & 0.17 & 0.35 & 0.59 \\
\hline K99 \& LM86 & 19.1 & 11.2 & 7.98 & 0.16 & 0.34 & 0.55 \\
\hline K99 \& N00 \& $\gamma_{\mathrm{a}}$ & 26.8 & 15.6 & 11.2 & 0.22 & 0.38 & 0.62 \\
\hline $\mathrm{K} 00 \& \mathrm{~N} 00 \& \gamma_{\mathrm{a}}$ & 25.6 & 15.8 & 9.86 & 0.22 & 0.38 & 0.61 \\
\hline K99* \& N00 \& $\gamma_{\mathrm{a}}$ & 29.9 & 17.4 & 12.5 & 0.25 & 0.40 & 0.65 \\
\hline $\mathrm{AN} 01 * \& \mathrm{~N} 00 \& \gamma_{\mathrm{a}}$ & 29.9 & 16.6 & 13.3 & 0.25 & 0.40 & 0.64 \\
\hline Temporally invariant & 29.7 & 16.2 & 13.6 & 0.24 & 0.41 & 0.65 \\
\hline Spatially uniform & 29.9 & 16.3 & 13.6 & 0.25 & 0.41 & 0.64 \\
\hline
\end{tabular}

a $37 \%$ reduction using $\mathrm{K} 99$ and LM86 to an $8 \%$ increase when neglecting air-side resistance. The largest ensemble spread in DMS emissions among the simulations is less than $0.06 \mu \mathrm{mol} \mathrm{m}{ }^{-2} \mathrm{~d}^{-1}$, which is negligible compared to the overall range of DMS emissions of the different model runs $\left(3.15 \mu \mathrm{mol} \mathrm{m}{ }^{-2} \mathrm{~d}^{-1}\right)$. By construction, the difference from the reference simulation is negligible in the temporally invariant and spatially uniform simulations and in the simulations with the rescaled concentration fields K99* and AN01* (Table 1).

The magnitudes of the simulated sulfur sources, sinks, and atmospheric burdens are also presented in Table 3. The budgets of sulfur species are very close to equilibrium in all simulations (sources approximately equal sinks). The reduction in DMS emission for simulations using K99 relative to those using $\mathrm{L} 10$ results in a reduction in daytime oxidation by $\mathrm{OH}$, while nighttime oxidation by $\mathrm{NO}_{3}$ does not change much. In contrast, both daytime and nighttime oxidation rates are affected equally when L10 is replaced with K00. The responses of oxidation rates to changes in DMS concentration patterns likely result from the distribution of the oxidants $\mathrm{OH}$ and $\mathrm{NO}_{3}$, which are specified in CanAM4.1.

The relationship between changes in the simulated atmospheric burdens of sulfur species and changes in DMS flux is approximately linear (Table 3). The largest changes occur in the DMS burden: the difference of $\sim 0.1 \mathrm{TgS}(61 \%)$ between L10 \& N00 and K99 \& LM86 is close to the difference in DMS flux $(68 \%)$ between these two simulations. The relative changes of $\mathrm{SO}_{2}$ and sulfate burdens are smaller than those of DMS because of the large background value for $\mathrm{SO}_{2}$ and sulfate from other sources (anthropogenic and volcanic).

The relationships of DMS, $\mathrm{SO}_{2}$, and $\mathrm{SO}_{4}^{2-}$ burdens with DMS flux are illustrated in Fig. 4. There are two distinct groups of simulations, depending on which DMS field is used. Regression lines computed for simulations with L10 (blue) and with K99 (purple) are almost parallel, indicating an approximately constant offset in burden between the K99 and L10 simulations. The sensitivity of atmospheric burdens of sulfur species to the spatial and temporal structure of DMS concentration is much smaller than to the global-mean flux. 


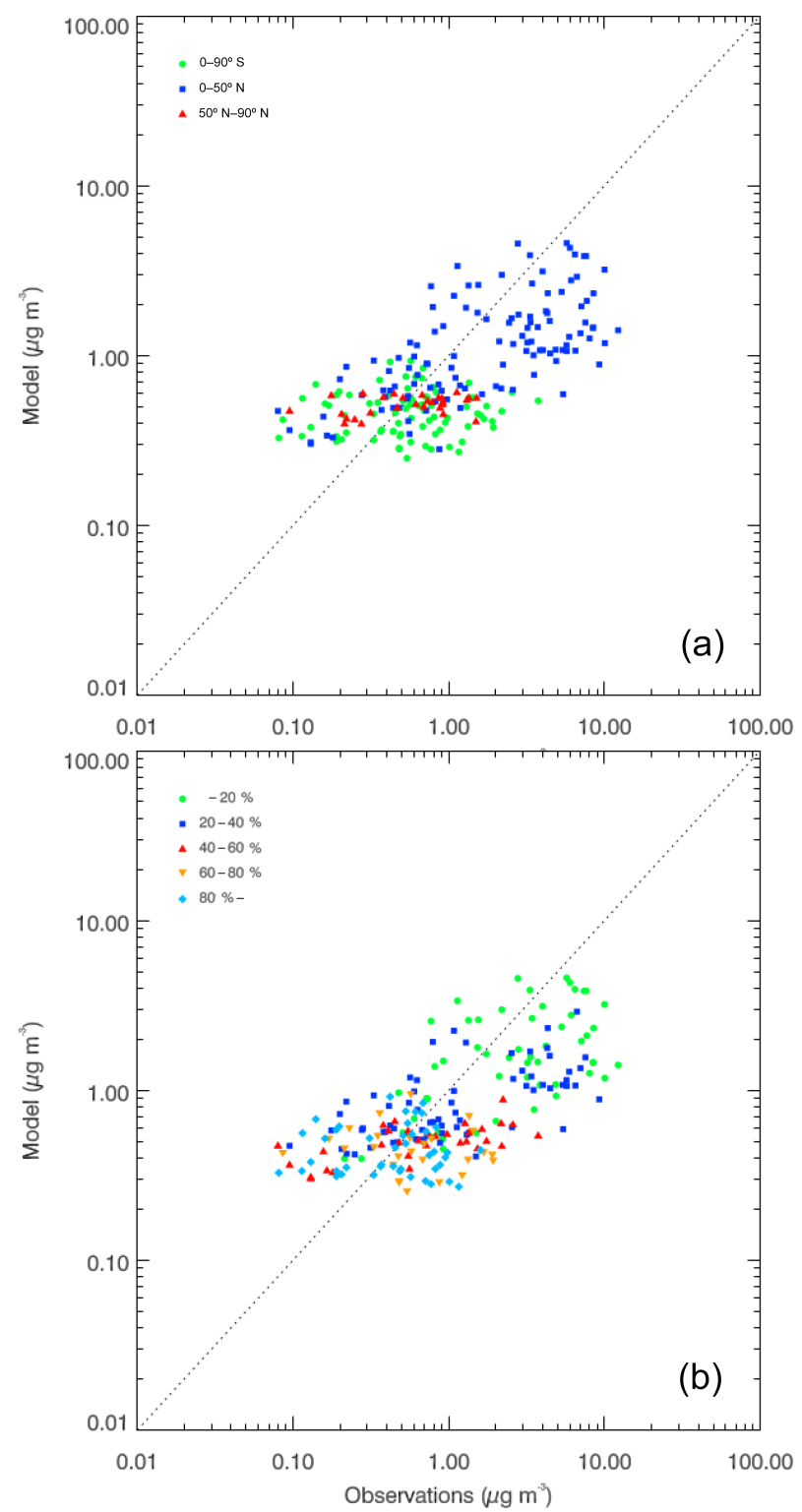

Figure 3. Correlation between observed and modelled nss- $\mathrm{SO}_{4}^{2-}$ using the control run (L10 \& N00 \& $\gamma_{\mathrm{a}}$ ). Modelled nss-SO ${ }_{4}^{2-}$ are derived from mean results of the simulation during the time period from 2004 to 2008. Observed concentrations are from 1995 to 2012 and matched to the nearest grid point and month of the model results. Comparison is done for (a) different latitude bands and (b) different fractions of sulfate that is produced by DMS emissions.

\subsection{Relationship between radiative effects, sulfate, and DMS}

To a first approximation, the relationship between TOA net radiation and the global-mean flux of DMS is linear (Fig. 5). Deviations from that linear relationship can be attributed to differences in spatial and temporal distribution among the DMS fields or internal variability. As with atmospheric $\mathrm{SO}_{2}$ and $\mathrm{SO}_{4}^{2-}$ burden, the relationship between the radiation
Table 4. Diagnostic and prognostic models used to estimate DMS concentrations in Fig. 6. These models are discussed in detail in Tesdal et al. (2016).

\begin{tabular}{ll}
\hline Name & Reference \\
\hline AN01 & Anderson et al. (2001) \\
AT04 & Aranami and Tsunogai (2004) \\
AU02 & Aumont et al. (2002) \\
BE04 & Belviso et al. (2004) \\
HadOCC & Collins et al. (2011) \\
HAMOCC & Kloster et al. (2006), \\
& Six and Maier-Reimer (2006) \\
MI09 & Miles et al. (2009) \\
PlankTOM & Vogt et al. (2010) \\
PISCES & Belviso et al. (2012) \\
POP-TGM & Elliott (2009) \\
SD02 & Simó and Dachs (2002) \\
VS07 & Vallina and Simó (2007) \\
\hline
\end{tabular}

fields and DMS flux can be divided into two classes of simulations using K99 or L10. The response of the radiative effect to differences in flux is smaller for K99-based simulations than for those based on L10. K99 generally has a larger radiative effect relative to the better-constrained L10, and this difference increases with increasing flux (i.e., with increasing wind speed and/or gas exchange coefficient).

Figure 5 shows that there is considerable variation in TOA net radiation depending on the strength of the ocean DMS source. Across the experiments, the range is $0.67 \mathrm{~W} \mathrm{~m}^{-2}$ (among ensemble means). The sensitivity to air-sea flux parameterization is particularly strong: the difference between LM86 and N00 in average flux (and thus in radiative effect) is greater than the difference among DMS concentration fields considered. The difference in net radiation between K00 and $\mathrm{L} 10$ is $0.33 \mathrm{~W} \mathrm{~m}^{-2}$, very similar to the value of $0.3 \mathrm{~W} \mathrm{~m}^{-2}$ estimated by Mahajan et al. (2015).

The spread of the individual ensemble members in Fig. 5 indicates the uncertainty in the radiation budget resulting from model internal variability over the 5-year period of the simulations, independent of the boundary conditions. This spread is on average $0.12 \mathrm{~W} \mathrm{~m}^{-2}$ (ranging from 0.04 to $0.19 \mathrm{~W} \mathrm{~m}^{-2}$ ) (compared to a range of $0.67 \mathrm{~W} \mathrm{~m}^{-2}$ across experiments).

The DMS concentration fields considered in this analysis are a relatively narrow subset of the observationally based or modelled climatologies considered in Tesdal et al. (2016). Use of some of these very different concentration fields would be expected to result in substantially different effects on the atmospheric radiation budget. A linear regression model constructed from the subset of simulations using N00 \& $\gamma_{\mathrm{a}}$ was used to obtain an estimate of the possible range of radiative perturbations corresponding to the entire range of DMS climatologies (Fig. 6). Offline reanalysisbased DMS fluxes were used in the estimation of DMS ra- 

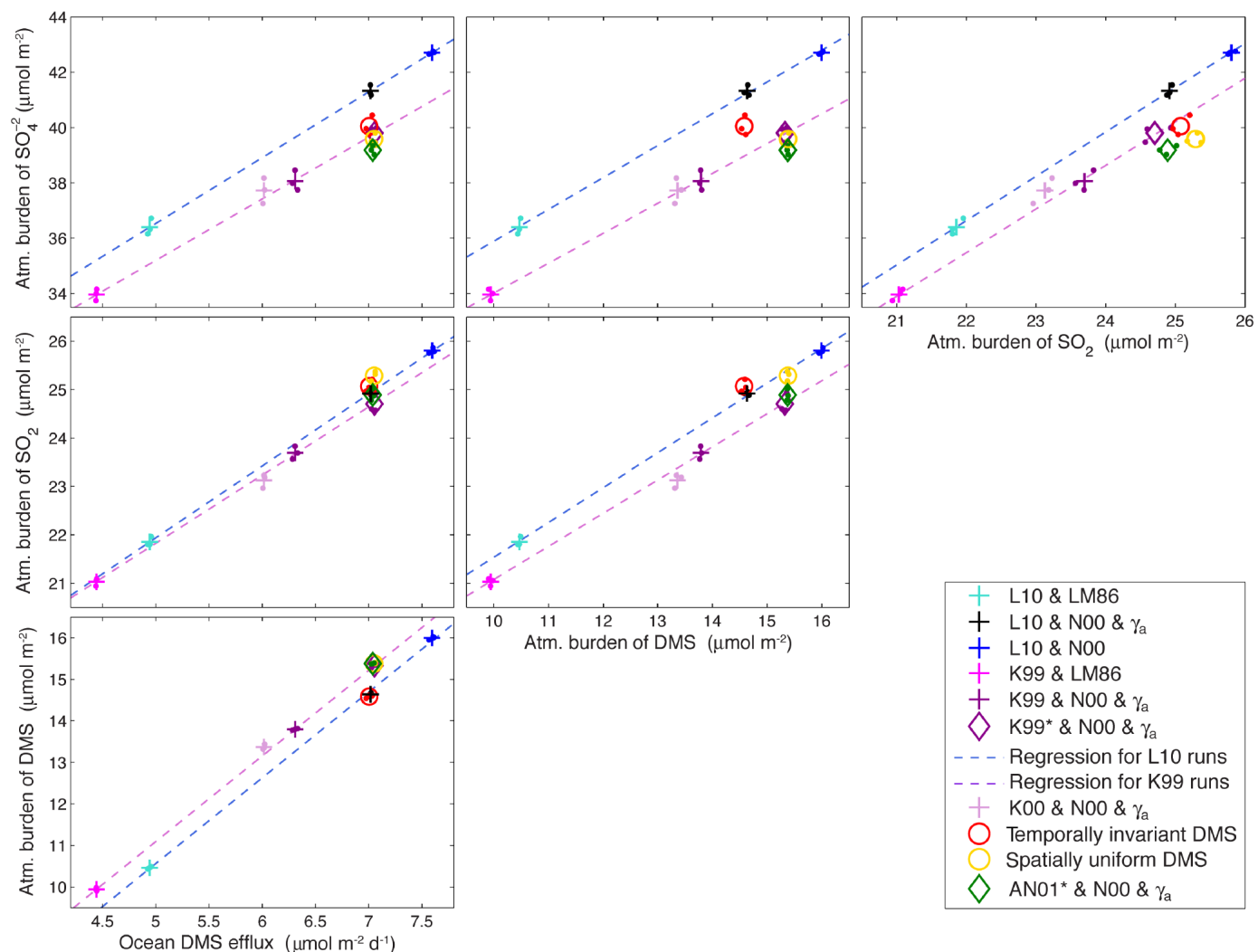

Figure 4. Scatter plots of atmospheric burdens of sulfur species vs. other species and ocean DMS emissions. Each dot represents the global and annual mean of individual ensemble members from the model experiments summarized in Table 1. Crosses indicate ensemble means for simulations with the original, unscaled flux fields. The regression lines were computed from the individual ensemble members corresponding to these unmodified DMS flux fields. Open circles denote ensemble mean of simulations with seasonality (red) or spatial pattern (yellow) removed. Open diamonds denote ensemble averages of simulations with DMS fields different from L10 but scaled to give the same globalmean flux. The first column shows atmospheric burdens of sulfur species $\left(\mathrm{SO}_{4}^{2-}, \mathrm{SO}_{2}, \mathrm{DMS}\right)$ against ocean emission of DMS, the second column shows atmospheric burdens of $\mathrm{SO}_{4}^{2-}$ and $\mathrm{SO}_{2}$ against DMS burden, and the third column shows atmospheric burden of $\mathrm{SO}_{4}^{2-}$ against the $\mathrm{SO}_{2}$ burden.

diative effects for those climatologies for which DMS fluxes from CanAM4.1 were not available. The range of perturbations to net TOA radiation across the different DMS climatologies with the same flux formulation is $0.75 \mathrm{~W} \mathrm{~m}^{-2}$, with L10 at the lower end since it produces the largest flux.

A similar estimate can be made for variation among the available piston velocity schemes, constructing the linear regression with model runs that have the same DMS field but different air-sea flux parameterizations (not shown). Using L10 as the DMS field and considering flux estimates obtained using N00, LM86, and a third parameterization of Wanninkhof (1992) (W92) produces a range of $1.04 \mathrm{~W} \mathrm{~m}^{-2}$.

Irrespective of differences in the spatial and temporal patterns of the DMS concentration field, the relationship between net TOA radiation and atmospheric sulfate burden is close to linear (Fig. 7). There is no evidence of distinct relationships depending on use of the L10 or K99 climatologies as seen in the relationship between DMS flux and TOA radiation. Evidently, these differences are associated with spatial and temporal differences in the oxidation of DMS to sulfate (Fig. 4).

Global means of individual radiation fields (shortwave cloud forcing, TOA clear-sky reflected flux, and TOA total reflected flux) are plotted against global-mean DMS flux and global-mean sulfate burden in Fig. 8. TOA clear-sky reflected flux represents the direct aerosol radiative effects, while shortwave cloud forcing represents the first indirect effect. In these simulations, the direct and first indirect effects are approximately equally sensitive to changes in DMS flux (or sulfate burden). The response of all-sky TOA total reflected flux to changes in global-mean DMS flux and atmospheric sulfate burden (Fig. 8) is similar to the total radiative effect (Figs. 5 and 7), and the range in total reflected flux is as large as that of total forcing among the different simulations. As the total radiative effect includes variation in longwave radiation while the reflected solar flux accounts only for shortwave radiation, our results confirm that the radiative effects associated with DMS are primarily in the shortwave. 


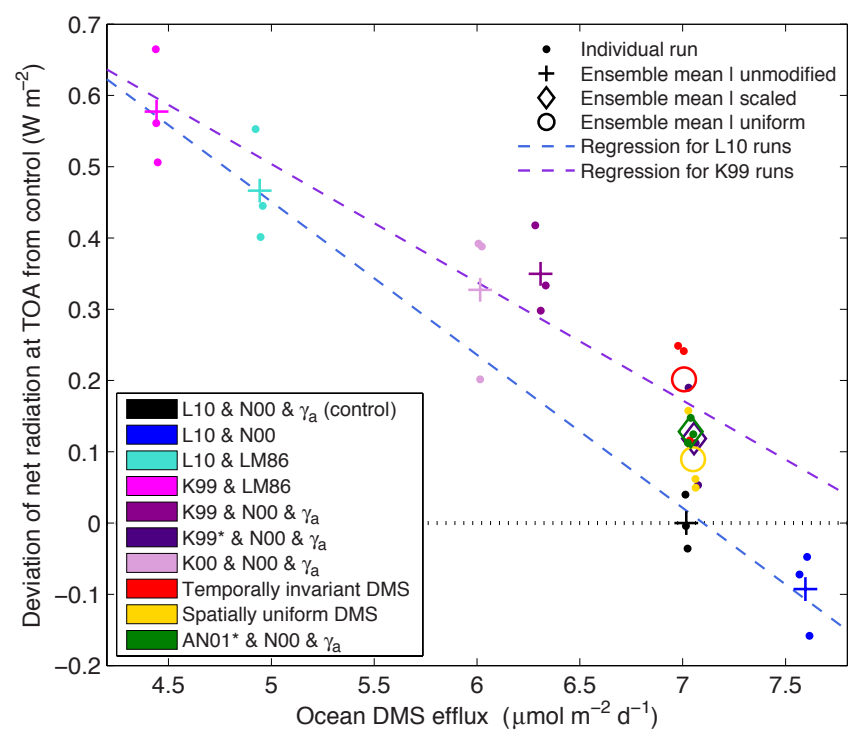

Figure 5. Change in global- and annual-mean net radiation at the top of the atmosphere between model experiments and control experiment relative to the global- and annual-mean flux of ocean DMS. Crosses represent the ensemble means of simulations with unmodified DMS fields. Open circles denote ensemble mean of simulations with seasonality (red) or spatial pattern (yellow) removed. Open diamonds denote simulations with DMS fields different from L10 but scaled to give the same global-mean flux. Individual ensemble members for each experiment are shown as dots of the same colour. Only data from individual runs with unmodified K99 (purple) or L10 (blue) DMS emissions are used for the corresponding regression lines.

The internal variability in either cloud forcing or clearsky reflected flux is generally larger than in the total reflected flux (which is approximately the sum of the first two) (Fig. 8). While the overall radiative effect of DMS fluxes in the model is estimated with reasonable precision with these experiments, larger ensembles or longer integrations may be required to achieve the same level of precision for the different components.

\subsection{The effect of DMS spatial and temporal structure on aerosols and radiative effects}

Suppressing either the spatial or temporal variability in ocean DMS concentration changes the concentration of sulfate aerosol and its effect on the TOA radiation budget (Figs. 5 and 8). While these changes are small, the ensemble spreads indicate that in some cases they are robust. The changes in global-mean DMS flux, oxidation rates, sulfur species burdens, and components of the TOA radiation budget between the control run and model runs with temporally invariant and spatially uniform DMS fields are shown in Fig. 9. For comparison, the changes from a simulation using L10 and N00 but neglecting the air resistance term are also shown.

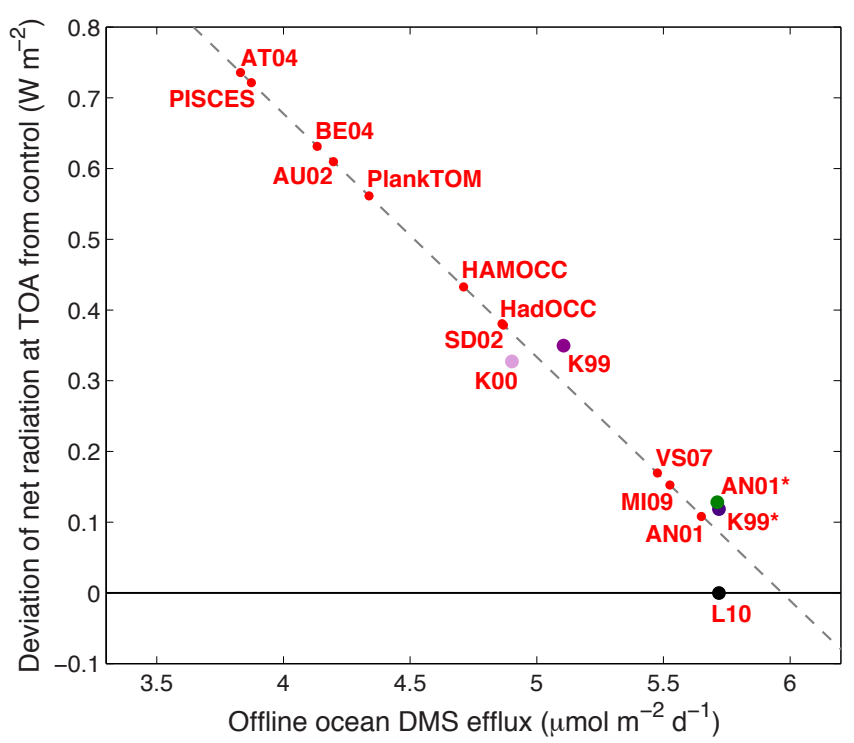

Figure 6. Estimated difference in global- and annual-mean net radiation at the top of the atmosphere (TOA) for the different climatologies considered in Tesdal et al. (2016) and the control simulation plotted against the global ocean efflux of DMS. DMS fluxes were computed offline using fields from the ERA-Interim reanalysis with NO0 \& $\gamma_{\mathrm{a}}$ as the air-sea transfer scheme (large filled circles). A linear regression for these runs only (grey dashed line) is used to derive estimates for other experiments (small red dots on regression line). The different climatologies considered are listed in Table 4.

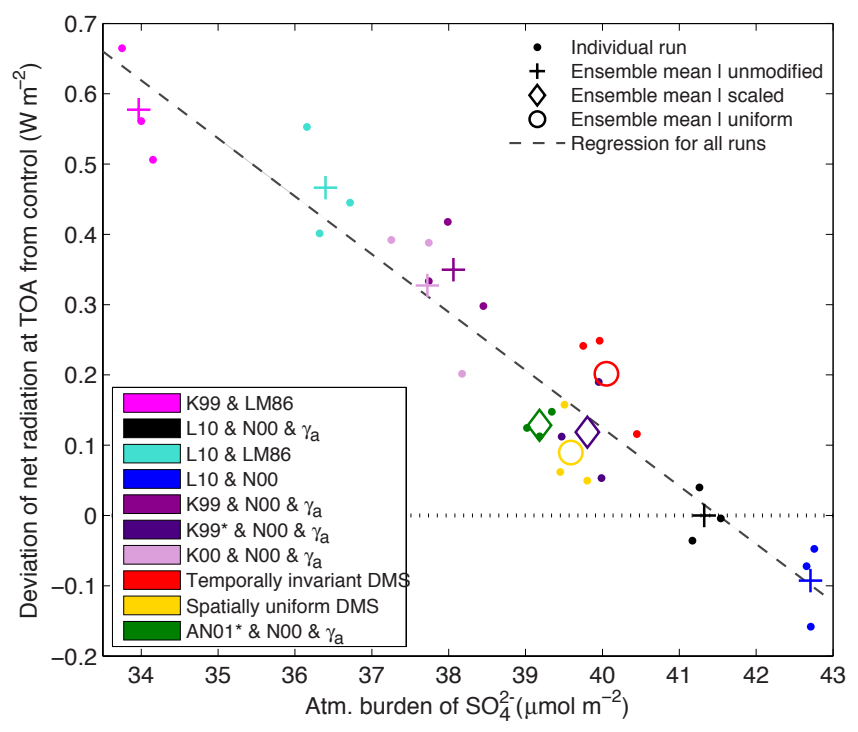

Figure 7. Deviation in global- and annual-mean net radiation at TOA from control plotted against the global- and annual-mean atmospheric burden of $\mathrm{SO}_{4}^{2-}$. Symbols are as in Fig. 5. All data points are used for the linear regression (grey dashed line).

The global-mean burden of a species in the atmosphere over a given time period is determined by the efficiency of internal sources and sinks, and indirectly by the transport. 


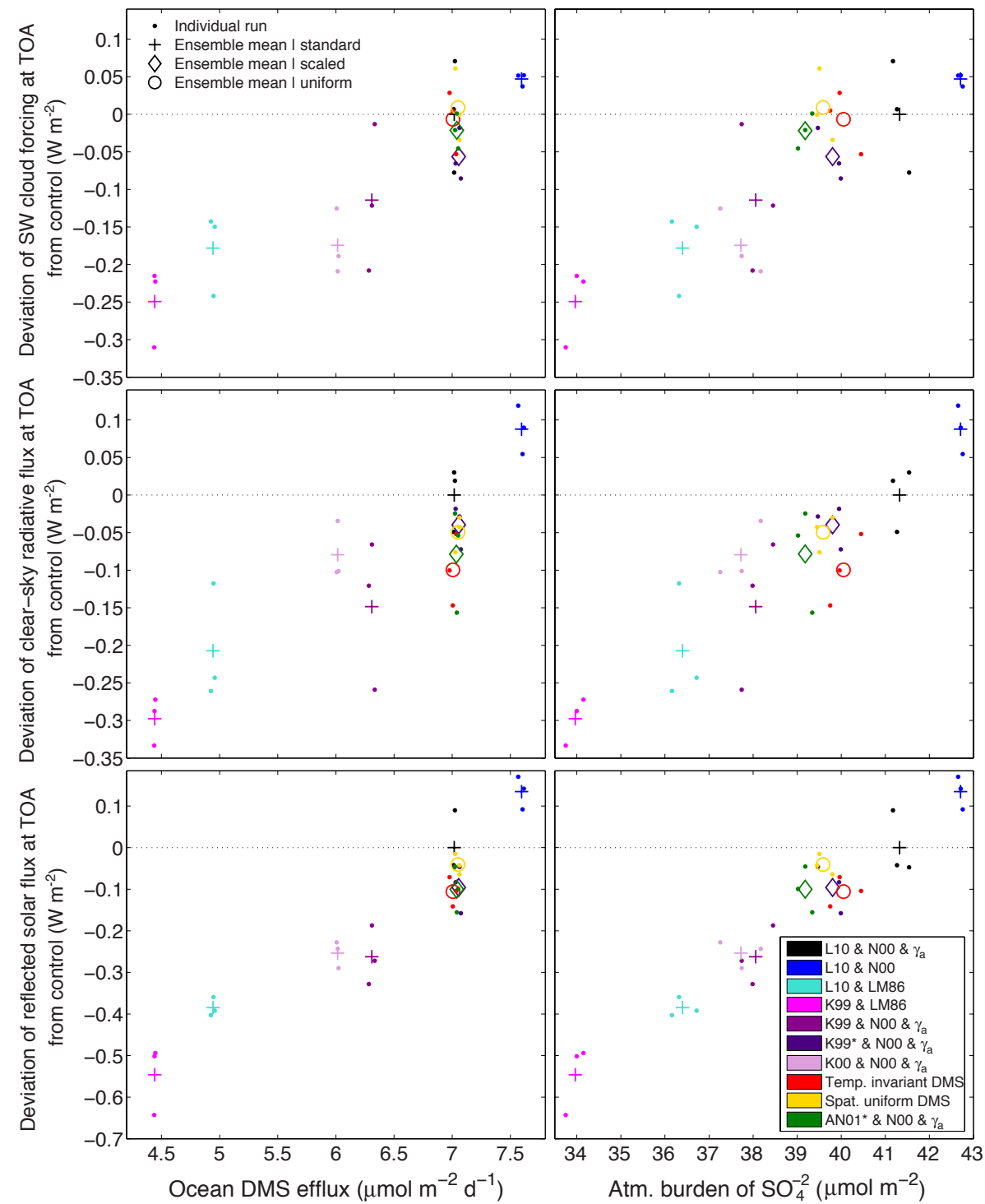

Figure 8. Deviation in global means of cloud forcing (upper panels), clear-sky reflected (middle panels), and total reflected irradiance (lower panels) at TOA from control plotted against global- and annual-mean ocean DMS flux (left) and global- and annual-mean atmospheric burden of $\mathrm{SO}_{4}^{2-}$ (right). Symbols are as in Fig. 5.

The time-mean state is effectively in equilibrium (Table 3), so global sulfur budgets are a simple sum over all internal sources, sinks, and fluxes between sulfur species. However, a balanced budget can be achieved with different values of the individual source and sink terms. The global rates of individual flux or sink processes are determined by the spatial and temporal relationships among the chemical species involved.

By construction, the spatially uniform and temporally invariant DMS concentration fields yield global-mean DMS fluxes that differ only slightly from the control simulation. However, there are substantial and statistically robust changes in the sink strengths (Fig. 9). The absence of spatial or temporal structure in the DMS concentration fields has different effects during day and night: daytime oxi- dation of DMS by $\mathrm{OH}$ is decreased in these simulations, balanced by an increase in nighttime oxidation by $\mathrm{NO}_{3}$. The simulation without air resistance shows an increase in global-mean DMS flux compared to the control of about $0.40 \mu \mathrm{mol} \mathrm{m}{ }^{-2} \mathrm{~d}^{-1}$, which is balanced by an increase in both oxidation rates.

The atmospheric burdens of all sulfur species increase significantly in the simulation without air resistance. As for the simulations with spatially or temporally averaged DMS concentrations, only the spatially uniform DMS simulation results in a change in oxidation patterns resulting in statistically robust increases in the burdens of both DMS and $\mathrm{SO}_{2}$. Interestingly, the increase in $\mathrm{SO}_{2}$ in these simulations is associated with a decrease in $\mathrm{SO}_{4}^{2-}$. A similar decrease in $\mathrm{SO}_{4}^{2-}$ 


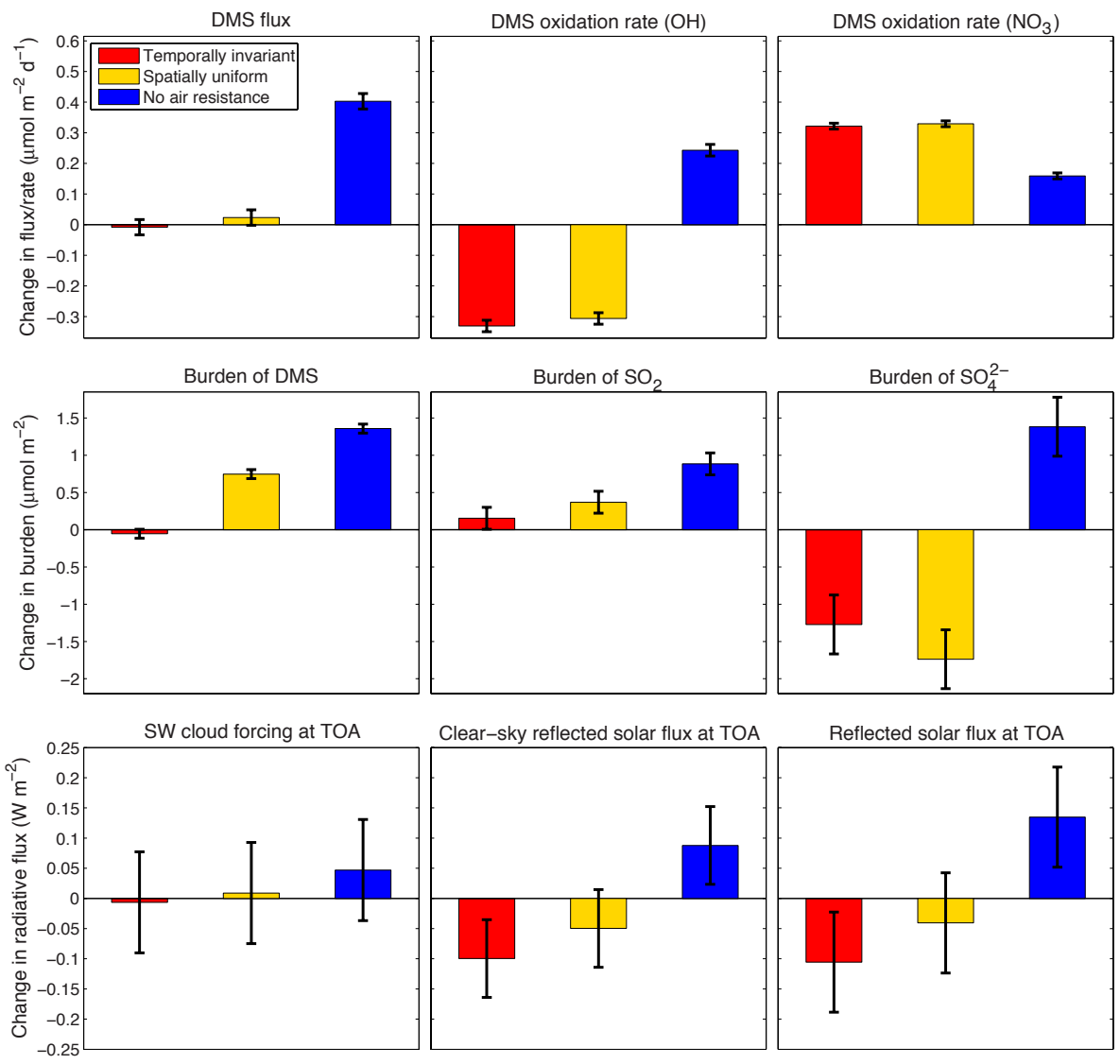

Figure 9. Absolute differences in global-mean flux, oxidation rates, sulfur burdens, and radiation between the control run and model runs with seasonally invariant (red) or spatially uniform (yellow) DMS concentration, as well as the L10 \& N00 model experiment (blue). Fluxes and oxidation rates of DMS are shown in the upper panels. The global-mean DMS flux includes terrestrial sources to ensure mass balance. The only sink for DMS is oxidation to $\mathrm{SO}_{2}$, which is shown for both oxidation pathways (oxidation by $\mathrm{OH}$ and $\mathrm{NO}_{3}$ radicals). Absolute changes in the atmospheric sulfur burdens of DMS, $\mathrm{SO}_{2}$, and $\mathrm{SO}_{4}^{2-}$ are shown in the middle panels. Bottom panels show absolute changes in cloud forcing, clear-sky reflected and total reflected shortwave flux. Total reflected flux is the sum of cloud and clear-sky reflected flux. To derive the error estimates, all treatments (control, temporally invariant, spatially uniform, and no air-side resistance) were pooled after their separate means were removed; error bars are \pm 2 standard deviations of the pooled data $(n=12)$. Statistical significance is determined by comparing the mean differences among the model runs with the corresponding error bars.

burdens is also seen in the simulations with temporally invariant DMS concentration fields, although neither the DMS nor $\mathrm{SO}_{2}$ burdens show statistically robust changes.

For all three of these sets of simulations, there is a much stronger response in the clear-sky reflected flux than in the shortwave cloud forcing. The changes in total reflected solar flux are statistically robust for both the simulations with temporally invariant surface concentration of DMS and those without air-side resistance. In all of these simulations, the effect on TOA cloud forcing is not significantly different from zero.

Taken together, these results indicate that the spatial and temporal distribution of DMS flux affects the aerosol direct radiative effect primarily by influencing the efficiency of oxidation of DMS to $\mathrm{SO}_{2}$ and $\mathrm{SO}_{4}^{2-}$. The effect on reflected solar fluxes of changes in $\mathrm{SO}_{4}^{2-}$ is larger for simulations with temporally invariant DMS concentration than for spatially uniform concentration, despite the change in $\mathrm{SO}_{4}^{2-}$ being larger in the latter case. This will be addressed in more detail in Sect. 4.

Note that the magnitudes (but not the signs) of changes in $\mathrm{SO}_{4}^{2-}$ resulting from suppressing spatial or temporal structure in the DMS concentration fields are the same as neglecting the air-side resistance term in the DMS flux formulation. Air-side resistance is often ignored in calculations of air-sea DMS fluxes. Our results indicate that the effect of neglecting this term is comparable in magnitude to the seemingly more dramatic change of entirely eliminating temporal or spatial structure in the DMS concentration fields. 


\section{Discussion}

The results presented in Sect. 3 demonstrate that, while the magnitude of the spatial and temporal mean DMS flux is linearly related to the mean DMS burden to a good first approximation, there are deviations from this linear relationship. A simple expression for the global spatial- and temporal-mean DMS budget is

$\left\langle\frac{\mathrm{d}}{\mathrm{d} t} \mathrm{DMS}\right\rangle=\langle E\rangle-\langle O \times \mathrm{DMS}\rangle$,

where the angle brackets denote global space- and timeaverages, $E$ is the emission field, and $O$ is the oxidation rate field (per unit of DMS concentration). At equilibrium, the rate of change vanishes, and

$\langle E\rangle=\langle O \times \mathrm{DMS}\rangle$

The upper three panels of Fig. 9 present simulated values of $\langle E\rangle$ and $\langle O \times \mathrm{DMS}\rangle$ for three sets of simulations (spatially uniform, temporally invariant, and neglecting air-side resistance).

If $O$ and DMS did not depend on space or time, then we could decompose $\langle O \times \mathrm{DMS}\rangle$ as $\langle O\rangle \times\langle\mathrm{DMS}\rangle$, and an exactly linear relation between global-mean flux and globalmean atmospheric burden would exist. The deviations from this relationship evident in Fig. 4 result from spatial and temporal correlations between the distribution of DMS and its sinks. Similarly, deviations from a purely linear relationship between spatial- and temporal-mean atmospheric burdens of $\mathrm{SO}_{2}$ and $\mathrm{SO}_{4}^{2-}$ result from correlations between $\mathrm{SO}_{2}$ and its oxidation rate. Atmospheric transport contributes to spatial and temporal correlations between atmospheric distributions of sulfur species and their sources and sinks. For example, some DMS emitted in the tropics will be transported by convective processes to the upper troposphere, where sinks are weaker. Similarly, the lifetime of sulfate transported to the upper troposphere is extended, as its primary sink is in lowto mid-tropospheric clouds. A detailed analysis of the spatial relationships among these processes is outside the scope of the present study.

As with the atmospheric burdens of sulfur species, the response of net TOA radiation to changes in mean DMS flux is linear to a first approximation (Fig. 5), with some scatter around this relationship resulting from model internal variability and differences in the spatial and temporal structure of the DMS fluxes. Our model simulations allow us to assess the relative sizes of three sources of uncertainty in the radiative effect of DMS emissions: (1) uncertainty in total emissions, (2) uncertainty in spatial/temporal pattern of fluxes, and (3) internal variability. Figure 5 indicates that, for the range of DMS climatologies and flux formulations considered, the size of the first of these uncertainties is about $0.7 \mathrm{~W} \mathrm{~m}^{-2}$, while the second and third are smaller (about $0.2 \mathrm{~W} \mathrm{~m}^{-2}$ ). While internal variability and uncertainty in spatial and tem- poral structure in DMS flux contribute to the overall uncertainty in the net radiation budget, our study shows that uncertainty in the global-mean flux is the dominant contributor. Uncertainties associated with model representations of atmospheric chemistry, cloud microphysics, and radiative transfer cannot be assessed using a single AGCM. Comparison of the magnitudes of these uncertainties to those we have considered is an interesting direction of future study.

The reduction in the radiative effect of DMS emissions resulting from suppressing the seasonal cycle in L10 is larger than that resulting from suppressing spatial variability (Fig. 5). This is consistent with the fact that DMS concentrations in L10 tend to be higher in summer (when changes to shortwave fluxes are particularly important) at mid- to high latitudes. As atmospheric residence times of sulfur species are on the order of a few to several days and their transport is primarily zonal, DMS emitted in the mid- or high latitudes will have its strongest effect in these latitude bands, and there will be a spatial correlation between DMS-derived sulfate aerosol concentration and aerosol radiative effects. These results suggest that, for global-mean responses, resolving the correct seasonal distribution of DMS fluxes is more important than resolving the spatial distribution, although neither is as important as the global-mean flux. However, we also note that the ensembles of the spatially uniform and temporally invariant simulations slightly overlap and it is possible that the difference between the two is a result of internal variability.

The fact that the deviations of TOA net radiation and reflected solar flux are similar in absolute value (Figs. 7 and 8) demonstrates that the climate response to DMS is dominated by shortwave fluxes. A weak response in the longwave may exist, but comparison of Figs. 7 and 8 suggests that it is smaller than internal variability. Furthermore, the strongly linear relationship between the atmospheric burden of $\mathrm{SO}_{4}^{2-}$ and total radiative effect (Fig. 7) demonstrates that simulated reductions in net TOA radiation are a direct response to increases in the atmospheric sulfate burden. Further statements about the causal relationship between changes in DMS flux and the global radiative effect are difficult because of the broad range of processes and feedbacks in the model.

Rough estimates of the range in net TOA radiation given the possible range in DMS flux are $0.75 \mathrm{~W} \mathrm{~m}^{-2}$ (among the range of available DMS fields) and $1.04 \mathrm{~W} \mathrm{~m}^{-2}$ (among all different flux parameterizations considered). Contrasting these uncertainties with the well-constrained radiative forcing of $+1.82 \pm 0.19 \mathrm{~W} \mathrm{~m}^{-2}$ due to the increase in atmospheric $\mathrm{CO}_{2}$ from 1750 to 2011 (Myhre et al., 2013) emphasizes the degree of uncertainty in DMS-derived aerosol forcing and the need to better constrain this quantity. Previous studies have found a relatively weak link between DMS fluxes and climate (e.g., Woodhouse et al., 2010; Kloster et al., 2007; Vallina et al., 2007). However, these studies may have a "weak effect" bias because of a low bias in DMS flux (Fig. 6), which would translate into a low bias in the radia- 
tive effect of DMS. The results of the current study show that there is a systematic deviation from the control run of up to $0.75 \mathrm{~W} \mathrm{~m}^{-2}$ for some DMS models and algorithms.

The uncertainty in DMS concentration estimates contributes substantially to uncertainties in present-day aerosol radiative forcing (Dentener et al., 2006; Carslaw et al., 2013), defined as the difference between present-day and preindustrial due to anthropogenic changes in the atmospheric aerosol burden (Myhre et al., 2013). While observationally based estimates can be made for the present day, these are not available for preindustrial conditions. Current understanding of the natural sulfur cycle indicates that most preindustrial sulfate aerosol originated from DMS and volcanic emissions (Carslaw et al., 2013). Uncertainty in estimates of these fluxes, which must be based on models in the absence of direct observations, will impact forcing estimates. The large uncertainty in DMS flux translates into uncertainty in preindustrial aerosol concentration, regardless of whether one assumes that DMS sources remain the same as or similar to preindustrial conditions. As DMS emissions may have changed from the preindustrial state, using fluxes estimated from present-day conditions increases this uncertainty.

Our estimates of climatic effects of DMS obtained using CanAM4.1 could be biased due to idealized assumptions about aerosol processes and the absence of a processbased representation of the indirect aerosol effect. These biases would be expected to be especially pronounced in the parts of the atmosphere least affected by anthropogenic emissions, such as the Southern Hemisphere. It is possible that sensitivity to the spatial and temporal distribution of DMS would change with an improved representation of cloud microphysics. Furthermore, instead of using specified atmospheric concentrations of the oxidants, a comprehensive tropospheric chemistry scheme could be used to achieve a more realistic modelling of atmospheric DMS oxidation.

This study did not investigate climate sensitivity to DMS flux in a coupled model; all model simulations were atmosphere-only. These experiments could be repeated in a coupled model setting which would allow for the feedbacks central to the CLAW hypothesis. Furthermore, a coupled model setup would allow for the evaluation of prognostic DMS modules, as opposed to using specified (climatological) fields. Such an analysis would allow exploration of the sensitivity of radiation and climate to specific parameters or mechanisms within the prognostic DMS formulations and to distinguish this from sensitivity to other aspects of the model. Two caveats regarding such an analysis are that DMS concentration fields resulting from existing prognostic models differ substantially from observations (Tesdal et al., 2016) and that internal variability would increase due to the longer timescales of oceanic variability.

The focus of our analysis has been the influence of DMS emissions on sulfate aerosol and its radiative effects, which can be used to estimate changes in global energy budgets. These measures provide a simple basis for quantifying as- pects of the climate response to imposed forcing agents, especially global-mean temperature, and hence are widely used in the scientific community (Myhre et al., 2013). We did not attempt to analyze regional and sub-annual variations in radiative effects of aerosols which are more difficult to analyze in a statistically robust way because internal variability is much larger relative to the forced response on regional scales. In general, regional relationships between aerosols, radiation, and temperature response can be complex and nonlinear. While these relationships are beyond the scope of the present study, we consider our estimates of global-scale effects to be robust and relatively insensitive to regional-scale processes.

\section{Conclusions}

Despite more than 30 years of concerted research on the issue, fundamental uncertainties remain regarding the spatial and temporal structure of surface ocean DMS concentrations and how best to model DMS fluxes (Tesdal et al., 2016). In this study, we have used the atmospheric component of a state-of-the-art global climate model (CanAM4.1) to assess the uncertainty in atmospheric sulfur burdens and their effect on the planetary radiation budget associated with uncertainties in DMS concentration fields and air-sea flux formulations. Our results indicate that, to a first approximation, the global spatial and temporal mean effect of DMS on net TOA radiation scales linearly with the spatial and temporal mean flux. Spatial and temporal correlations between model sulfur species (DMS, $\mathrm{SO}_{2}$, and $\mathrm{SO}_{4}^{2-}$ ) and their sinks result in deviations from this linear relationship that exceed internal variability, but these deviations are relatively small. This result suggests that on a global scale, it is most important to have an accurate estimate of the global DMS flux, while resolving the exact spatial and temporal distribution is of less importance. Neglect of air-side resistance in the flux parameterization was shown to have a comparable (or even larger) effect on net TOA radiation than suppressing spatial or temporal structure in the DMS concentration field. From the perspective of global climate, accurate formulation of surface fluxes is as or more important than accurate representation of sea surface DMS concentrations.

A comprehensive view of the global-scale uncertainties is important for understanding the role of DMS in the climate system. Uncertainty about the global DMS concentration translates to uncertainty about global estimates of DMS flux, aerosol burdens, and their radiative effects. These uncertainties limit the confidence with which we can make statements about the importance of DMS in the climate system, and leave open the possibility that changes in DMS fluxes could alter future climate in as-yet-unexpected ways. 


\section{Data availability}

The CanAM4.1 model output used in this study, as well as the co-located datasets of simulated and observed nss- $\mathrm{SO}_{4}^{2-}$, is available at http://collaboration.cmc.ec.gc.ca/cmc/cccma/ data/jchristian/dms/.

The L10 data were obtained from the SOLAS website (http://www.bodc.ac.uk/solas_integration/ implementation_products/group1/dms/). The K00 dataset was obtained from the NCAR Data Archive (http://rda.ucar.edu/datasets/ds289.2/). The data used to construct the AN01 climatology are described in detail in Tesdal et al. (2016). ERA-Interim reanalysis products were obtained from the European Centre for Medium-Range Weather Forecasts (http://www.ecmwf.int/en/research/ climate-reanalysis/era-interim). The data of observed nss$\mathrm{SO}_{4}^{2-}$ was retrieved from the NOAA PMEL Atmospheric Chemistry Data Server (http://saga.pmel.noaa.gov/data/).

\section{The Supplement related to this article is available online at doi:10.5194/acp-16-10847-2016-supplement.}

Acknowledgements. J.-E. Tesdal would like to acknowledge support from the Natural Sciences and Engineering Research Council of Canada (NSERC) CREATE Training Program in Interdisciplinary Climate Science. A. H. Monahan acknowledges support from the NSERC Discovery Grants Program. The authors also thank Kelly McCusker and the two anonymous reviewers for their helpful comments on this manuscript.

We thank Matthew Woodhouse for his help in accessing the K00 dataset. We also acknowledge the assistance of Timothy Bates and Jim Johnson in retrieving nss- $\mathrm{SO}_{4}^{2-}$ measurements from the NOAA PMEL Atmospheric Chemistry Data Server (http://saga.pmel.noaa.gov/data/).

Edited by: D. Spracklen

Reviewed by: two anonymous referees

\section{References}

Anderson, T. R., Spall, S. A, Yool, A., Cipollini, P., Challenor, P. G., and Fasham, M. J. R.: Global fields of sea surface dimethylsulfide predicted from chlorophyll, nutrients and light, J. Marine Syst., 30, 1-20, doi:10.1016/S0924-7963(01)00028-8, 2001.

Andreae, M. O. and Crutzen, P. J.: Atmospheric aerosols: Biogeochemical sources and role in atmospheric chemistry, Science, 276, 1052-1058, doi:10.1126/science.276.5315.1052, 1997.

Andreae, M. O. and Raemdonck, H.: Dimethyl sulfide in the surface ocean and the marine atmosphere: A global view, Science, 221, 744-747, doi:10.1126/science.221.4612.744, 1983.

Aranami, K. and Tsunogai, S.: Seasonal and regional comparison of oceanic and atmospheric dimethylsulfide in the northern North Pacific: Dilution effects on its concentration during winter, J. Geophys. Res.-Atmos., 109, D12303, doi:10.1029/2003JD004288, 2004.

Asher, E. C., Merzouk, A., and Tortell, P. D.: Fine-scale spatial and temporal variability of surface water dimethylsufide (DMS) concentrations and sea-air fluxes in the NE Subarctic Pacific, Mar. Chem., 126, 63-75, doi:10.1016/j.marchem.2011.03.009, 2011.

Aumont, O., Belviso, S., and Monfray, P.: Dimethylsulfoniopropionate (DMSP) and dimethylsulfide (DMS) sea surface distributions simulated from a global three-dimensional ocean carbon cycle model, J. Geophys. Res.-Oceans, 107, 3029, doi:10.1029/1999JC000111, 2002.

Bates, T. S., Lamb, B. K., Guenther, A., Dignon, J., and Stoiber, R. E.: Sulfur emissions to the atmosphere from natural sources, J. Atmos. Chem., 14, 315-337, doi:10.1007/BF00115242, 1992.

Bates, T. S., Kiene, R. P., Wolfe, G. V., Matrai, P. A., Chavez, F. P., Buck, K. R., Blomquist, B. W., and Cuhel, R. L.: The cycling of sulfur in surface seawater of the northeast Pacific, J. Geophys. Res.-Oceans, 99, 7835-7843, doi:10.1029/93JC02782, 1994

Bellouin, N., Mann, G. W., Woodhouse, M. T., Johnson, C., Carslaw, K. S., and Dalvi, M.: Impact of the modal aerosol scheme GLOMAP-mode on aerosol forcing in the Hadley Centre Global Environmental Model, Atmos. Chem. Phys., 13, 3027 3044, doi:10.5194/acp-13-3027-2013, 2013.

Belviso, S., Bopp, L., Moulin, C., Orr, J. C., Anderson, T. R., Aumont, O., Chu, S., Elliott, S., Maltrud, M. E., and Simó, R.: Comparison of global climatological maps of sea surface dimethyl sulfide, Global Biogeochem. Cy., 18, GB3013, doi:10.1029/2003GB002193, 2004.

Belviso, S., Masotti, I., Tagliabue, A., Bopp, L., Brockmann, P., Fichot, C., Caniaux, G., Prieur, L., Ras, J., Uitz, J., Loisel, H., Dessailly, D., Alvain, S., Kasamatsu, N., and Fukuchi, M.: DMS dynamics in the most oligotrophic subtropical zones of the global ocean, Biogeochemistry, 110, 215-241, doi:10.1007/s10533011-9648-1, 2012.

Berge, E.: Coupling of wet scavenging of sulphur to clouds in a numerical weather prediction model, Tellus Ser. B, 45, 1-22, doi:10.1034/j.1600-0889.1993.00001.x, 1993.

Bopp, L., Aumont, O., Belviso, S., and Monfray, P.: Potential impact of climate change on marine dimethyl sulfide emissions, Tellus Ser. B, 55, 11-22, doi:10.1034/j.1600-0889.2003.042.x, 2003.

Brasseur, G. P., Hauglustaine, D. A., Walters, S., Rasch, P. J., Müller, J.-F., Granier, C., and Tie, X. X.: MOZART, a global chemical transport model for ozone and related chemical tracers: 1. Model description, J. Geophys. Res.-Atmos., 103, 28265 28289, doi:10.1029/98JD02397, 1998.

Cameron-Smith, P., Elliott, S., Maltrud, M., Erickson, D., and Wingenter, O.: Changes in dimethyl sulfide oceanic distribution due to climate change, Geophys. Res. Lett., 38, L07704, doi:10.1029/2011GL047069, 2011.

Carslaw, K. S., Lee, L. A., Reddington, C. L., Pringle, K. J., Rap, A., Forster, P. M., Mann, G. W., Spracklen, D. V., Woodhouse, M. T., Regayre, L. A., and Pierce, J. R.: Large contribution of natural aerosols to uncertainty in indirect forcing, Nature, 503, 67-71, doi:10.1038/nature12674, 2013.

Charlson, R. J., Lovelock, J. E., Andreae, M. O., and Warren, S. G. Oceanic phytoplankton, atmospheric sulphur, cloud albedo and climate, Nature, 326, 655-661, doi:10.1038/326655a0, 1987. 
Collins, W. J., Bellouin, N., Doutriaux-Boucher, M., Gedney, N., Halloran, P., Hinton, T., Hughes, J., Jones, C. D., Joshi, M., Liddicoat, S., Martin, G., O'Connor, F., Rae, J., Senior, C., Sitch, S., Totterdell, I., Wiltshire, A., and Woodward, S.: Development and evaluation of an Earth-System model - HadGEM2, Geosci. Model Dev., 4, 1051-1075, doi:10.5194/gmd-4-10512011, 2011.

Croft, B., Lohmann, U., and von Salzen, K.: Black carbon ageing in the Canadian Centre for Climate modelling and analysis atmospheric general circulation model, Atmos. Chem. Phys., 5, 19311949, doi:10.5194/acp-5-1931-2005, 2005.

Dee, D. P., Uppala, S. M., Simmons, A. J., Berrisford, P., Poli, P., Kobayashi, S., Andrae, U., Balmaseda, M. A., Balsamo, G., Bauer, P., Bechtold, P., Beljaars, A. C. M., van de Berg, L., Bidlot, J., Bormann, N., Delsol, C., Dragani, R., Fuentes, M., Geer, A. J., Haimberger, L., Healy, S. B., Hersbach, H., Hólm, E. V., Isaksen, L., Kållberg, P., Köhler, M., Matricardi, M., McNally, A. P., Monge-Sanz, B. M., Morcrette, J.-J., Park, B.-K., Peubey, C., de Rosnay, P., Tavolato, C., Thépaut, J.-N., and Vitart, F.: The ERA-Interim reanalysis: configuration and performance of the data assimilation system, Q. J. Roy. Meteor. Soc., 137, 553-597, doi:10.1002/qj.828, 2011.

Dentener, F., Kinne, S., Bond, T., Boucher, O., Cofala, J., Generoso, S., Ginoux, P., Gong, S., Hoelzemann, J. J., Ito, A., Marelli, L., Penner, J. E., Putaud, J.-P., Textor, C., Schulz, M., van der Werf, G. R., and Wilson, J.: Emissions of primary aerosol and precursor gases in the years 2000 and 1750 prescribed data-sets for AeroCom, Atmos. Chem. Phys., 6, 4321-4344, doi:10.5194/acp-64321-2006, 2006.

Dentener, F. J. and Crutzen, P. J.: A three-dimensional model of the global ammonia cycle, J. Atmos. Chem., 19, 331-369, doi:10.1007/BF00694492, 1994.

Dufresne, J.-L., Quaas, J., Boucher, O., Denvil, S., and Fairhead, L.: Contrasts in the effects on climate of anthropogenic sulfate aerosols between the 20th and the 21st century, Geophys. Res. Lett., 32, L21703, doi:10.1029/2005GL023619, 2005.

Elliott, S.: Dependence of DMS global sea-air flux distribution on transfer velocity and concentration field type, J. Geophys. Res.Biogeo., 114, G02001, doi:10.1029/2008JG000710, 2009.

Gabric, A. J., Simó, R., Cropp, R. A., Hirst, A. C., and Dachs, J.: Modeling estimates of the global emission of dimethylsulfide under enhanced greenhouse conditions, Global Biogeochem. Cy., 18, GB2014, doi:10.1029/2003GB002183, 2004.

Gabric, A. J., Qu, B., Matrai, P., and Hirst, A. C.: The simulated response of dimethylsulfide production in the Arctic Ocean to global warming, Tellus Ser. B, 57, 391-403, doi:10.1111/j.16000889.2005.00163.x, 2005.

Gondwe, M., Krol, M., Gieskes, W., Klaassen, W., and de Baar, H.: The contribution of ocean-leaving DMS to the global atmospheric burdens of DMS, MSA, $\mathrm{SO}_{2}$, and $\mathrm{NSS} \mathrm{SO}_{4}^{=}$, Global Biogeochem. Cy., 17, 1056, doi:10.1029/2002GB001937, 2003.

Grandey, B. S. and Wang, C.: Enhanced marine sulphur emissions offset global warming and impact rainfall, Sci. Rep., 5, 13055, doi:10.1038/srep13055, 2015.

Gunson, J. R., Spall, S. A., Anderson, T. R., Jones, A., Totterdell, I. J., and Woodage, M. J.: Climate sensitivity to ocean dimethylsulphide emissions, Geophys. Res. Lett., 33, L07701, doi:10.1029/2005GL024982, 2006.
Halloran, P. R., Bell, T. G., and Totterdell, I. J.: Can we trust empirical marine DMS parameterisations within projections of future climate?, Biogeosciences, 7, 1645-1656, doi:10.5194/bg-71645-2010, 2010.

Hurrell, J. W., Hack, J. J., Shea, D., Caron, J. M., and Rosinski, J.: A new sea surface temperature and sea ice boundary dataset for the Community Atmosphere Model, J. Climate, 21, 5145-5153, doi:10.1175/2008JCLI2292.1, 2008.

Kettle, A. J. and Andreae, M. O.: Flux of dimethylsulfide from the oceans: A comparison of updated data sets and flux models, J. Geophys. Res.-Atmos., 105, 26793-26808, doi:10.1029/2000JD900252, 2000.

Kettle, A. J., Andreae, M. O., Amouroux, D., Andreae, T. W., Bates, T. S., Berresheim, H., Bingemer, H., Boniforti, R., Curran, M. A. J., DiTullio, G. R., Helas, G., Jones, G. B., Keller, M. D., Kiene, R. P., Leck, C., Levasseur, M., Malin, G., Maspero, M., Matrai, P., McTaggart, A. R., Mihapoulos, N., Nguyen, B. C., Novo, A., Putaud, J. P., Rapsomanikis, S., Roberts, G., Schebeske, G., Sharma, S., Simó, R., Staubes, R., Turner, S., and Uher, G.: A global database of sea surface dimethylsulfide (DMS) measurements and a procedure to predict sea surface DMS as a function of latitude, longitude, and month, Global Biogeochem. Cy., 13, 399-444, doi:10.1029/1999GB900004, 1999.

Kloster, S., Feichter, J., Maier-Reimer, E., Six, K. D., Stier, P., and Wetzel, P.: DMS cycle in the marine ocean-atmosphere system a global model study, Biogeosciences, 3, 29-51, doi:10.5194/bg3-29-2006, 2006.

Kloster, S., Six, K. D., Feichter, J., Maier-Reimer, E., Roeckner, E., Wetzel, P., Stier, P., and Esch, M.: Response of dimethylsulfide (DMS) in the ocean and atmosphere to global warming, J. Geophys. Res.-Biogeo., 112, G03005, doi:10.1029/2006JG000224, 2007.

Koch, D., Schulz, M., Kinne, S., McNaughton, C., Spackman, J. R., Balkanski, Y., Bauer, S., Berntsen, T., Bond, T. C., Boucher, O., Chin, M., Clarke, A., De Luca, N., Dentener, F., Diehl, T., Dubovik, O., Easter, R., Fahey, D. W., Feichter, J., Fillmore, D., Freitag, S., Ghan, S. J., Ginoux, P., Gong, S., Horowitz, L., Iversen, T., Kirkevåg, A., Klimont, Z., Kondo, Y., Krol, M., Liu, X., Miller, R., Montanaro, V., Moteki, N., Myhre, G., Penner, J. E., Perlwitz, J., Pitari, G., Reddy, S., Sahu, L., Sakamoto, H., Schuster, G., Schwarz, J. P., Seland, Ø., Stier, P., Takegawa, N., Takemura, T., Textor, C., van Aardenne, J. A., and Zhao, Y.: Evaluation of black carbon estimations in global aerosol models, Atmos. Chem. Phys., 9, 9001-9026, doi:10.5194/acp-9-9001-2009, 2009.

Lamarque, J.-F., Bond, T. C., Eyring, V., Granier, C., Heil, A., Klimont, Z., Lee, D., Liousse, C., Mieville, A., Owen, B., Schultz, M. G., Shindell, D., Smith, S. J., Stehfest, E., Van Aardenne, J., Cooper, O. R., Kainuma, M., Mahowald, N., McConnell, J. R., Naik, V., Riahi, K., and van Vuuren, D. P.: Historical (1850-2000) gridded anthropogenic and biomass burning emissions of reactive gases and aerosols: methodology and application, Atmos. Chem. Phys., 10, 7017-7039, doi:10.5194/acp10-7017-2010, 2010.

Lana, A., Bell, T. G., Simó, R., Vallina, S. M., Ballabrera-Poy, J., Kettle, A. J., Dachs, J., Bopp, L., Saltzman, E. S., Stefels, J., Johnson, J. E., and Liss, P. S.: An updated climatology of surface dimethlysulfide concentrations and emission fluxes 
in the global ocean, Global Biogeochem. Cy., 25, GB1004, doi:10.1029/2010GB003850, 2011.

Liss, P. S. and Merlivat, L.: Air-sea gas exchange rates: introduction and synthesis, in: The Role of Air-Sea Exchange in Geochemical Cycling, edited by: Buat-Ménard, P., vol. 185 of NATO ASI Series, Springer Netherlands, 113-127, 1986.

Lohmann, U., von Salzen, K., McFarlane, N., Leighton, H. G., and Feichter, J.: Tropospheric sulfur cycle in the Canadian general circulation model, J. Geophys. Res.-Atmos., 104, 26833-26858, doi:10.1029/1999JD900343, 1999.

Ma, X., von Salzen, K., and Cole, J.: Constraints on interactions between aerosols and clouds on a global scale from a combination of MODIS-CERES satellite data and climate simulations, Atmos. Chem. Phys., 10, 9851-9861, doi:10.5194/acp-10-98512010, 2010.

Mahajan, A. S., Fadnavis, S., Thomas, M. A., Pozzoli, L., Gupta, S., Royer, S.-J., Saiz-Lopez, A., and Simó, R.: Quantifying the impacts of an updated global dimethyl sulfide climatology on cloud microphysics and aerosol radiative forcing, J. Geophys. Res.Atmos., 120, 2524-2536, doi:10.1002/2014JD022687, 2015.

Malin, G., Turner, S. M., and Liss, P. S.: Sulfur: The plankton/climate connection, J. Phycol., 28, 590-597, doi:10.1111/j.0022-3646.1992.00590.x, 1992.

McGillis, W. R., Dacey, J. W. H., Frew, N. M., Bock, E. J., and Nelson, R. K.: Water-air flux of dimethylsulfide, J. Geophys. Res.Oceans, 105, 1187-1193, doi:10.1029/1999JC900243, 2000.

Miles, C. J., Bell, T. G., and Lenton, T. M.: Testing the relationship between the solar radiation dose and surface DMS concentrations using in situ data, Biogeosciences, 6, 1927-1934, doi:10.5194/bg-6-1927-2009, 2009.

Moss, R. H., Edmonds, J. A., Hibbard, K. A., Manning, M. R., Rose, S. K., van Vuuren, D. P., Carter, T. R., Emori, S., Kainuma, M., Kram, T., Meehl, G. A., Mitchell, J. F. B., Nakicenovic, N., Riahi, K., Smith, S. J., Stouffer, R. J., Thomson, A. M., Weyant, J. P., and Wilbanks, T. J.: The next generation of scenarios for climate change research and assessment, Nature, 463, 747-756, doi:10.1038/nature08823, 2010.

Myhre, G., Shindell, D., Bréon, F.-M., Collins, W., Fuglestvedt, J., Huang, J., Koch, D., Lamarque, J.-F., Lee, D., Mendoza, B., Nakajima, T., Robock, A., Stephens, G., Takemura, T., and Zhang, H.: Anthropogenic and natural radiative forcing, in: Climate Change 2013: The Physical Science Basis. Contribution of Working Group I to the Fifth Assessment Report of the Intergovernmental Panel on Climate Change, edited by: Stocker, T. F., Qin, D., Plattner, G.-K., Tignor, M., Allen, S. K., Boschung, J., Nauels, A., Xia, Y., Bex, V., and Midgley, P. M., Cambridge University Press, Cambridge, United Kingdom and New York, NY, USA, 2013.

Nightingale, P. D., Malin, G., Law, C. S., Watson, A. J., Liss, P. S., Liddicoat, M. I., Boutin, J., and Upstill-Goddard, R. C.: In situ evaluation of air-sea gas exchange parameterizations using novel conservative and volatile tracers, Global Biogeochem. Cy., 14, 373-387, doi:10.1029/1999GB900091, 2000.

Quaas, J., Ming, Y., Menon, S., Takemura, T., Wang, M., Penner, J. E., Gettelman, A., Lohmann, U., Bellouin, N., Boucher, O., Sayer, A. M., Thomas, G. E., McComiskey, A., Feingold, G., Hoose, C., Kristjánsson, J. E., Liu, X., Balkanski, Y., Donner, L. J., Ginoux, P. A., Stier, P., Grandey, B., Feichter, J., Sednev, I., Bauer, S. E., Koch, D., Grainger, R. G., Kirkevåg, A.,
Iversen, T., Seland, Ø., Easter, R., Ghan, S., Rasch, P. J., Morrison, H., Lamarque, J.-F., Iacono, M. J., Kinne, S., and Schulz, M.: Aerosol indirect effects - general circulation model intercomparison and evaluation with satellite data, Atmos. Chem. Phys., 9, 8697-8717, doi:10.5194/acp-9-8697-2009, 2009.

Quinn, P. K. and Bates, T. S.: The case against climate regulation via oceanic phytoplankton sulphur emissions, Nature, 480, 5156, doi:10.1038/nature10580, 2011.

Schulz, M., Textor, C., Kinne, S., Balkanski, Y., Bauer, S., Berntsen, T., Berglen, T., Boucher, O., Dentener, F., Guibert, S., Isaksen, I. S. A., Iversen, T., Koch, D., Kirkevåg, A., Liu, X., Montanaro, V., Myhre, G., Penner, J. E., Pitari, G., Reddy, S., Seland, $\varnothing .$, Stier, P., and Takemura, T.: Radiative forcing by aerosols as derived from the AeroCom present-day and pre-industrial simulations, Atmos. Chem. Phys., 6, 5225-5246, doi:10.5194/acp-65225-2006, 2006.

Simó, R. and Dachs, J.: Global ocean emission of dimethylsulfide predicted from biogeophysical data, Global Biogeochem. Cy., 16, 1078, doi:10.1029/2001GB001829, 2002.

Six, K. D. and Maier-Reimer, E.: What controls the oceanic dimethylsulfide (DMS) cycle? A modeling approach, Global Biogeochem. Cy., 20, GB4011, doi:10.1029/2005GB002674, 2006.

Six, K. D., Kloster, S., Ilyina, T., Archer, S. D., Zhang, K., and Maier-Reimer, E.: Global warming amplified by reduced sulphur fluxes as a result of ocean acidification, Nat. Clim. Change, 3, 975-978, doi:10.1038/nclimate1981, 2013.

Slingo, J. M.: The development and verification of a cloud prediction scheme for the ECMWF model, Q. J. Roy. Meteor. Soc., 113, 899-927, doi:10.1002/qj.49711347710, 1987.

Spiro, P. A., Jacob, D. J., and Logan, J. A.: Global inventory of sulfur emissions with $1^{\circ} \times 1^{\circ}$ resolution, J. Geophys. Res.-Atmos., 97, 6023-6036, doi:10.1029/91JD03139, 1992.

Stefels, J., Steinke, M., Turner, S., Malin, G., and Belviso, S.: Environmental constraints on the production and removal of the climatically active gas dimethylsulphide (DMS) and implications for ecosystem modelling, Biogeochemistry, 83, 245-275, doi:10.1007/s10533-007-9091-5, 2007.

Stevens, B. and Feingold, G.: Untangling aerosol effects on clouds and precipitation in a buffered system, Nature, 461, 607-613, doi:10.1038/nature08281, 2009.

Tesdal, J.-E., Christian, J. R., Monahan, A. H., and von Salzen, K.: Evaluation of diverse approaches for estimating sea-surface DMS concentration and air-sea exchange at global scale, Environ. Chem., 13, 390-412, doi:10.1071/EN14255, 2016.

Thomas, M. A., Suntharalingam, P., Pozzoli, L., Rast, S., Devasthale, A., Kloster, S., Feichter, J., and Lenton, T. M.: Quantification of DMS aerosol-cloud-climate interactions using the ECHAM5-HAMMOZ model in a current climate scenario, Atmos. Chem. Phys., 10, 7425-7438, doi:10.5194/acp-10-74252010, 2010.

Thomas, M. A., Suntharalingam, P., Pozzoli, L., Devasthale, A., Kloster, S., Rast, S., Feichter, J., and Lenton, T. M.: Rate of non-linearity in DMS aerosol-cloud-climate interactions, Atmos. Chem. Phys., 11, 11175-11183, doi:10.5194/acp-1111175-2011, 2011.

Tortell, P. D.: Small-scale heterogeneity of dissolved gas concentrations in marine continental shelf waters, Geochem. Geophy. Geosy., 6, Q11M04, doi:10.1029/2005GC000953, 2005. 
Tortell, P. D., Guéguen, C., Long, M., Payne, C., Lee, P., and DiTullio, G.: Spatial variability and temporal dynamics of surface water $\mathrm{pCO}_{2}, \Delta \mathrm{O}_{2} / \mathrm{Ar}$ and dimethylsulfide in the Ross Sea, Antarctica, Deep-Sea Res. Pt. I, 58, 241-259, doi:10.1016/j.dsr.2010.12.006, 2011.

Vallina, S. M. and Simó, R.: Strong relationship between DMS and the solar radiation dose over the global surface ocean, Science, 315, 506-508, doi:10.1126/science.1133680, 2007.

Vallina, S. M., Simó, R., and Manizza, M.: Weak response of oceanic dimethylsulfide to upper mixing shoaling induced by global warming, P. Natl. Acad. Sci. USA, 104, 16004-16009, doi:10.1073/pnas.0700843104, 2007.

Vogt, M., Vallina, S. M., Buitenhuis, E. T., Bopp, L., and Le Quéré, C.: Simulating dimethylsulphide seasonality with the Dynamic Green Ocean Model PlankTOM5, J. Geophys. Res.-Oceans, 115, C06021, doi:10.1029/2009JC005529, 2010.

von Salzen, K., Leighton, H. G., Ariya, P. A., Barrie, L. A., Gong, S. L., Blanchet, J.-P., Spacek, L., Lohmann, U., and Kleinman, L. I.: Sensitivity of sulphate aerosol size distributions and $\mathrm{CCN}$ concentrations over North America to $\mathrm{SO}_{x}$ emissions and $\mathrm{H}_{2} \mathrm{O}_{2}$ concentrations, J. Geophys. Res.-Atmos., 105, 97419765, doi:10.1029/2000JD900027, 2000. von Salzen, K., Scinocca, J. F., McFarlane, N. A., Li, J., Cole, J. N. S., Plummer, D., Verseghy, D., Reader, M. C., Ma, X., Lazare, M., and Solheim, L.: The Canadian Fourth Generation Atmospheric Global Climate Model (CanAM4). Part I: Representation of physical processes, Atmos. Ocean, 51, 104-125, doi:10.1080/07055900.2012.755610, 2013.

Wanninkhof, R.: Relationship between wind speed and gas exchange over the ocean, J. Geophys. Res.-Oceans, 97, 7373-7382, doi:10.1029/92JC00188, 1992.

Woodhouse, M. T., Carslaw, K. S., Mann, G. W., Vallina, S. M., Vogt, M., Halloran, P. R., and Boucher, O.: Low sensitivity of cloud condensation nuclei to changes in the sea-air flux of dimethyl-sulphide, Atmos. Chem. Phys., 10, 7545-7559, doi:10.5194/acp-10-7545-2010, 2010.

Woodhouse, M. T., Mann, G. W., Carslaw, K. S., and Boucher, O.: Sensitivity of cloud condensation nuclei to regional changes in dimethyl-sulphide emissions, Atmos. Chem. Phys., 13, 2723 2733, doi:10.5194/acp-13-2723-2013, 2013. 